\title{
Improvements of simulated Western North Atlantic current system and impacts on the AMOC
}

\author{
C. Talandier ${ }^{a, *}$, J. Deshayes ${ }^{a}$, A-M. Treguier ${ }^{a}$, X. Capet $^{b}$, R. Benshila ${ }^{b}$, L. Debreu ${ }^{c}$, R. Dussin ${ }^{d}$, \\ J-M. Molines ${ }^{d}, G$. Madec ${ }^{b, e}$
}

a LPO, CNRS-IFREMER-IRD-UBO, Plouzané, France

b LOCEAN-IPSL, CNRS-UPMC-IRD-MNHN, Paris, France

c LJK, Université Joseph Fourier, Grenoble, France

d LGGE, CNRS-UJF, Grenoble, France

e NOC, Southampton, United Kingdom

*: Corresponding author : Claude Talendier, email address : claude.talandier@ifremer.fr

\begin{abstract}
:
Previous studies have shown that low horizontal resolution (of the order of $1^{\circ}$ ) ocean models, hence climate models, are not able to adequately represent boundary currents nor mesoscale processes which affect the dynamics and thermohaline circulation of the ocean. While the effect of mesoscale eddies can be parameterized in low resolution models, boundary currents require relatively high horizontal resolution. We clarify the impact of increasing the resolution on the North Atlantic circulation, with emphasis on the Atlantic Meridional Overturning Circulation (AMOC), by embedding a $1 / 8^{\circ}$ nest covering the North Atlantic into a global $1 / 2^{\circ}$ model.

Increasing the resolution in the nest leads to regional improvements of the circulation and thermohaline properties in the Gulf Stream area, for the North Atlantic Current, in the subpolar gyre and the Nordic Seas, consistent with those of previous studies. In addition, we show that the Deep Western Boundary Current dense water transport increases with the nest, from the overflows down to Flemish Cap, due to an increase in the Denmark Strait overflow as well as dense water formation in the subpolar gyre. This increases the Atlantic Meridional Overturning Circulation in density space by about $8 \mathrm{~Sv}$ in the Subpolar gyre in the nested configuration. When exiting the Labrador Sea around $53^{\circ} \mathrm{N}$ we illustrate that the Deep Western Boundary Current successively interacts with the upper ocean circulation composed with the North Atlantic Current in the intergyre region, the Northern Recirculation Gyre, and the Gulf Stream near Cape Hatteras. This surface/deep current interaction seems to induce an increase of the AMOC intensity in depth-space, giving rise to an AMOC maximum near $35^{\circ} \mathrm{N}$. This process is missing in the configuration without nesting. At $26.5^{\circ} \mathrm{N}$, the AMOC is $4 \mathrm{~Sv}$ larger in the nested configuration and is in good agreement with observations. Finally, beyond the nest imprint (i.e. in the low resolution area) in the South Atlantic the AMOC maximum at $40^{\circ} \mathrm{S}$ is $3 \mathrm{~Sv}$ larger at the end of the simulation meaning that information is able to propagate outside the nest without being fully damped. This underlines the benefit of using the nest for a reasonable computing time compared to a fully global higher resolution configuration.
\end{abstract}

\section{Highlights}

Two global simulations that differ in their resolution in the North Atlantic are compared. At high resolution, the dynamics as well as thermohaline properties are improved. DWBC intensity and pathway compare better with observations in the higher resolution. The AMOC- $\sigma$ is $8 \mathrm{~Sv}$ larger in the high resolution simulation. Interaction between surface and deep currents contributes to increasing the AMOC-z.

Keywords : Deep Western Boundary Current ; Atlantic Meridional Overturning Circulation ; North Atlantic Current ; Gulf Stream ; Subpolar Gyre 


\section{Introduction}

processes are not explicitly resolved which leads to major well-known biases,

24 in particular along oceanic western boundaries. Griffies et al. (2009) present a 25

With respect to the ocean's contribution to climate, namely the transport of heat from the equator poleward, the Atlantic Ocean stands out as it transports heat northward in both hemispheres. This transport is associated with the Atlantic Meridional Overturning Circulation (AMOC) that combines a northward near-surface flow (from the surface down to approximately 1000 m depth), referred to as the "upper limb", with a compensating southward flow at depth known as the "lower limb". The latter is mainly composed of the Deep Western Boundary Current (DWBC) carrying North Atlantic Deep Waters (NADW). The AMOC is thought to play a key role in the Earth's climate system (Srokosz et al., 2012), but it remains unclear what controls its strength and structure. Various modeling experiments have been developed to complement existing observations in this perspective.

Coupled climate models are useful to investigate climate change issues because they are able to simulate past and present climate, where they can be evaluated against observations, and attempt to predict future climate assuming scenarios for external (including anthropogenic) forcings. Because these models combine various components of the Earth's climate, and must be spun up for long time periods to reach equilibrium, ocean and atmosphere components have resolutions of the order of $1^{\circ}$ (as for the $5^{\text {th }}$ phase of the Coupled Model Intercomparison Project). At this resolution, many oceanic review of those biases based on an intercomparison of forced ocean models at 
this resolution. In the North Atlantic subtropical gyre, the separation of the Gulf Stream from the American East Coast, near Cape Hatteras, is not well reproduced by these models. As the simulated Gulf Stream follows the coast north of Cape Hatteras, a warm bias is observed in place of the relatively cold Northern Recirculation Gyre. In the intergyre region, the simulated North Atlantic Current (NAC) tends to flow eastward offshore Grand Banks without forming the well-observed NorthWest Corner (NWC). This results in a large cold and fresh anomaly off Newfoundland, also called "the Blue spot of death" by modelers (Gnanadesikan et al., 2007). In atmosphere-ocean coupled models, these oceanic anomalies significantly affect the atmospheric circulation, which influences the ocean in return via biases in surface buoyancy fluxes over the subpolar gyre (Weese and Bryan, 2006). Indeed, the peak winter mixed layer depths at high latitudes in the North Atlantic are most often badly located and/or overestimated in low-resolution ocean and climate models compared to observations; the overestimation may be due to the lack of restratification processes (Chanut et al., 2008). Because these oceanic biases have different signatures depending on model settings and parameters, the ocean model experiments by Griffies et al. (2009), albeit forced by the same atmospheric conditions, have very different AMOC strength and structure.

Numerical developments are underway to improve low resolution ocean models, developing parameterizations of unresolved processes or improving numerical schemes. For example, Penduff et al. (2007) illustrate the improvements of DWBC structure and intensity in a global $1 / 4^{\circ}$ configuration, 
obtained when combining partial steps (better representing the ocean topography) and an energy-enstrophy conserving momentum advection scheme (Le Sommer et al., 2009). Nevertheless, there are key physical processes for AMOC that cannot be easily reproduced nor mimicked. The large-scale adjustment of AMOC to dense water formation seems to be initiated by the propagation of Kelvin waves and/or topographic waves along the western boundary, as suggested by theoretical numerical experiments (Herbaut et al., 2006; Johnson and Marshall, 2002); the grid resolution and lateral viscosity are known to affect the propagation of such waves (Hsieh, 1983). Restratification of the upper ocean, after dense water formation by convection, involves mesoscale (Chanut et al., 2008; Katsman et al., 2004) and submesoscale processes (Fox-Kemper and Ferrari, 2008). Finally, subtropical and subpolar western boundary currents are intrinsically trapped in a layer where viscosity, lateral friction and non-linearities cannot be neglected. Several studies have attempted to clarify the impact of small scale processes on the large-scale circulation in the North Atlantic, by comparing models of varying resolution. Smith et al. (2000) and Bryan et al. (2007) suggest that a resolution of $1 / 10^{\circ}$ or higher is needed to reproduce the Gulf Stream separation properly. Treguier et al. (2005) investigate four ocean models of resolution spanning $\left[1 / 6^{\circ}-1 / 12^{\circ}\right]$ in the subpolar gyre, and suggest that increased horizontal resolution allows a better representation of large scale ocean features. Spence et al. (2012) also find that the representation of western boundary currents is improved with resolution. Because these regional circulation features contribute to AMOC, their improvement is beneficial to the accurate simulation of AMOC. Our objective is to revisit these regional 
improvements due to increased resolution, in order to clarify their impact on AMOC.

The impact of spatial resolution on AMOC has been investigated by Hodson and Sutton (2012) in a coupled ocean-atmosphere model: they compare experiments after increasing the horizontal resolution of the ocean from $1^{\circ}$ to $1 / 3^{\circ}$ (atmospheric resolution is increased as well, from $1.25^{\circ}$ latitude $\mathrm{x}$ $1.875^{\circ}$ longitude to $\left.0.83^{\circ} \times 1.25^{\circ}\right)$. They find that the AMOC structure and strength is similar between both experiments, which may be due to the fact that their "high" oceanic resolution does not resolve mesoscale processes in the North Atlantic at subtropical and higher latitudes, and hence remains in the "eddy-permitting" regime. Here, we increase horizontal resolution from $1 / 2^{\circ} \times 1 / 2^{\circ} \cos \phi$ to $1 / 8^{\circ} \times 1 / 8^{\circ} \cos \phi$ ( $\phi$ latitude) in the North Atlantic, extending the eddy-resolving regime over the subtropical gyre. This ensures a substantial improvement of Gulf Stream dynamics, which has repercussions for the whole North Atlantic and, subsequently, the AMOC, which contrasts with Hodson and Sutton's (2012) results. Rather than increasing the resolution of our whole global ocean model, which is expensive even in forced mode, we develop a configuration that includes a fully interactive nest covering the North Atlantic. This ocean configuration is forced by atmospheric reanalyses; thus we cannot investigate the impact of improved western boundary currents on the atmosphere. Still, this study may be useful in improving climate models as it demonstrates how increasing spatial resolution improves North Atlantic circulation and AMOC. The original model configuration, as well as experiments and forcings, are described in section 2. In section 3, 
we highlight regional improvements, similar to those obtained in previous studies. Then we demonstrate their impact on the AMOC (section 4). We discuss our results in conjunction with those of previous studies, including Hodson and Sutton (2012), in section 5, and then conclude (section 6).

\section{Model configuration}

Experiments analysed hereafter are set_up with the NEMO modeling platform (Madec, 2008), using the OPA Ocean General Circulation Model (OGCM) and sea-ice LIM2 components associated with Adaptative Grid Refinement In Fortran (AGRIF) (Debreu et al., 2008) capability. Three simulations presented in this study rely on two configurations that only differ in horizontal resolution in the North Atlantic.

\subsection{Domain and grid characteristics}

In this paper we refer to three numerical experiments. Two of them rely on global configurations at $1 / 2^{\circ}$ named ORCA_REF and ORCA_NOG; the first is our reference experiment, the second is a sensitivity experiment which differs from ORCA_REF only by the omission of the Gent and McWilliams parameterization. The third experiment is called ERNA and is the highlight of this study.

In detail, ORCA_REF and ORCA_NOG are based on the ORCA tripolar and quasi-isotropic grid (Madec, 2008) at $1 / 2^{\circ}$ nominal resolution at the equator with $722 \times 551$ grid points (Biastoch et al., 2008). ERNA combines a coarse grid that is the same as ORCA_REF, with a higher-resolution grid covering the North Atlantic from $20^{\circ} \mathrm{N}$ to $75^{\circ} \mathrm{N}$ (Fig. 1). A spatial grid ratio 
of 4 allows the model to reach a $1 / 8^{\circ}$ resolution over this area with $724 \times 632$ grid points. The "two-ways" interaction between fine and coarse grids in ERNA allows the exchange of information along lateral boundaries of the nest (for 3D variables including the baroclinic transport of mass, heat and salt) and over the whole surface of the nest (for $2 \mathrm{D}$ variables such as the barotropic transport and sea-ice characteristics). The sea-ice is explicitly simulated in both coarse and fine grids. The ORCA $1 / 2^{\circ}$ coarse grid is marginally "Eddy-Permitting" in equatorial regions. The $1 / 8^{\circ}$ grid fully resolves mesoscale eddies from the southern boundary of the domain to $45^{\circ} \mathrm{N}$ and can be considered "Eddy-Permitting" northward. Experiments share the same 64 vertical geopotential levels with an increasing cell thickness from $6 \mathrm{~m}$ near the surface to around $200 \mathrm{~m}$ in the deep ocean. The last level thickness just above the sea floor adjusts to the actual topography which allows a better representation of bathymetry (Barnier et al., 2006). The bathymetry is interpolated from ETOPO2v2 below $300 \mathrm{~m}$ depth and GEBCO One minute grid, version 2.0 in coastal areas, with no horizontal smoothing (except when required by AGRIF along the lateral boundaries of the nest).

\subsection{Numerical aspects}

The model solves the three-dimensional Primitive Equations in spherical coordinates discretized on an Arakawa C-grid with the hydrostatic, Boussinesq and non-divergent flow assumptions among a few others. The linearized free-surface formulation (Roullet and Madec, 2000) is used. The vertical mixing is parameterized with a turbulent kinetic energy closure scheme (Blanke and Delecluse, 1993), improved by including a surface wave breaking parameterization (Mellor and Blumberg, 2004) and an energetically consistent 

171 scheme.

\section{2.3. Experiments}

173 174

time and space discretization (Burchard 2002; Marsaleix et al. 2008). The convective processes are mimicked using an enhanced vertical diffusion parameterization (increasing vertical viscosity/diffusity to $10 \mathrm{~m}^{2} \mathrm{~s}^{-1}$ where static instability occurs). On the coarse (respectively fine) grid a harmonic isopycnal diffusion of $600(100) \mathrm{m}^{2} s^{-1}$ and a biharmonic viscosity along geopotential surfaces of $12 \times 10^{11}\left(8.5 \times 10^{9}\right) \mathrm{m}^{4} s^{-1}$ are used. To keep a constant Reynolds grid number, the diffusive and viscous coeficients decrease from the equatorial nominal value (given just above) poleward and are respectively proportional to $\max [\Delta \mathrm{x}, \Delta \mathrm{y}] / \Delta_{\max }$ and $\max [\Delta \mathrm{x}, \Delta \mathrm{y}]^{3} / \Delta_{\text {max }}^{3} ; \Delta \mathrm{x}$ and $\Delta \mathrm{y}$ are the zonal and meridional grid spacing and $\Delta_{\max }$ is the maximum of $\Delta \mathrm{x}$ and $\Delta \mathrm{y}$ taken over the whole ocean grid. The effect of mesoscale eddies on tracers relies on the Gent and McWilliams parameterization $\left(1000 \mathrm{~m}^{2} \mathrm{~s}^{-1}\right)$; it is used in the ORCA_REF and ERNA experiments (outside the nest only, where the resolution is $1 / 2^{\circ}$ ) while it is not activated in the ORCA_NOG one. A partial-slip sidewall boundary condition is used in momentum equations in all experiments; i.e. the tangential velocity at the coast is set to half the offshore velocity (Benshila et al., 2013). The discrete formulation used for the momentum advection term in the coarse grid is the vector form associated with an energy and enstrophy conserving scheme following the recommendation of Le Sommer et al. (2009) and Penduff et al. (2007) for the vorticity term, while in the fine grid the flux form is combined with an energy conserving

Experiments start from rest and are initialised with the January Levitus et al. (1998) climatology. After a 3-year spinup using year 1989, they run 
over 20-years (1990-2009) with interannual ERA-Interim atmospheric conditions derived from reanalysis. Turbulent fluxes are computed through CORE bulk formulae from Large and Yeager (2004), using ERA-Interim atmospheric state variables. Precipitations come from satellite products (Brodeau et al. 2010). ERA-Interim short and long wave radiative fluxes are reduced respectively by $3 \%$ and $6 \%$, on large scales only, to better match GEWEX satellite observations in the latitude band $\left[40^{\circ} \mathrm{S}-40^{\circ} \mathrm{N}\right.$ ) (following the methodology of Large and Yeager (2008) for ISCCP products). Temperature and humidity state variables are also adjusted in high latitudes (north of $70^{\circ} \mathrm{N}$ ) following the methodology detailed in Brodeau et al. (2010). To limit salinity drift that is partly due to precipitation uncertainties, a moderate Sea Surface Salinity (SSS) relaxation towards Levitus et al. (1998) monthly climatology is applied with a 60 -day timescale over the upper $10 \mathrm{~m}$. This relaxation is restricted to large scale oceanic structures selected by a Shapiro filter on SSS. In addition, a linear tapering of this relaxation is applied along continental shelves (from 0 at the coast to $1400 \mathrm{~km}$ offshore), so almost no relaxation occurs in the Labrador and Irminger Seas.

\section{Regional improvements}

As a first step toward understanding the impact of model resolution on AMOC, we compare among simulations the circulation and hydrography in a few key regions of the Western North Atlantic current system. In the following, the time-mean characteristics if not specified, are computed over 
1990-2009.

\subsection{The Subtropical Gyre}

Numerous studies contributed to explaining the Gulf Stream detachment from the coast near Cape Hatteras (e.g. Spall, 1996). Notwithstanding, modeling the Gulf Stream pathways remains a challenge in OGCMs even in higher resolution configurations (Bryan et al. 2007; Chassignet and Garraffo 2001).

As done in previous studies (e.g. Coetlogon et al. (2006)), the position of the Gulf Stream is identified and compared with observations using the $17^{\circ} \mathrm{C}$ isotherm near $177 \mathrm{~m}$ depth (Fig.2). Its climatological mean position in ERNA shows a fairly good agreement with Levitus climatology, while ORCA_REF simulates an excessively northward position downstream with a Gulf Stream trapped along the continental rise. The latter is associated with the absence of the Northern Recirculation Gyre whose cyclonic barotropic transport reaches $20 \mathrm{~Sv}$ in ERNA. Further east around $45^{\circ} \mathrm{W}$, the $17^{\circ} \mathrm{C}$ isotherm in ERNA shows a northward loop that is associated with the "Mann-Eddy". This pattern is not resolved in either the Levitus climatology or in ORCA_REF and may be due to the insufficient resolution of both products ( $1^{\circ}$ for observations, $1 / 2^{\circ}$ for ORCA_REF) and, for the model output, to erroneous reproduction of the circulation along the Grand Banks, in relation with the North Atlantic pathways.

The amplitude of surface Eddy Kinetic Energy (EKE), averaged over the period 1993-2009 and computed from five-days-mean outputs in ERNA, compares well with observations (Ducet et al., 2000) and exceeds $1800 \mathrm{~cm}^{2} s^{-2}$ (Fig. 3). The shape is slightly different but such a bias is common to oceanic 
models at this resolution (Smith et al., 2000; Bryan et al., 2007). In ERNA, the $1200 \mathrm{~cm}^{2} \mathrm{~s}^{-2}$ contour is wider in the meridional direction to the west of $60^{\circ} \mathrm{W}$ and extends less to the east than observed, although the impact of New England seamounts near $61^{\circ} \mathrm{W}$ is in good agreement with observations (Ezer, 1994). The $1200 \mathrm{~cm}^{2} \mathrm{~s}^{-2}$ contour also reaches further upstream of Cape Hatteras along the Gulf Stream path in ERNA compared to observations, possibly due to an overly unstable simulated Gulf Stream related to the advection scheme used or/and to the lateral boundary condition. Note that the $50 \mathrm{~cm}^{2} \mathrm{~s}^{-2}$ EKE pattern related to the Azores current in ERNA is also in good agreement with observations. In ORCA_REF, EKE along the Gulf Stream pathway (not shown) is very weak (below $50 \mathrm{~cm}^{2} \mathrm{~s}^{-2}$ ), which is primarily due to spatial resolution but also to the use of Gent and McWilliams parameterization (GM) (the experiment ORCA_NOG without GM reaches EKE levels of $100-150 \mathrm{~cm}^{2} s^{-2}$ in this area).

The vertical structure of the subtropical circulation along the western boundary is compared to repeated observations along Line W (courtesy of R. Curry, see Toole et al., 2011, their Fig.4; see Fig. 1 for the section location). ERNA shows a remarkable extension of the Gulf Stream core over the top $1000 \mathrm{~m}$ depth and a clear shift from the continental slope, as observed. The signature of southward flowing DWBC is visible at depth, albeit with smaller amplitude than observed. In ORCA_REF, the Gulf Stream core is excessively diffuse and does not penetrate deeper than $500 \mathrm{~m}$ and the DWBC core is clearly missing.

Observations (e.g. Bower and Hunt, 2000) revealed interactions between the 
upper ocean circulation near the Gulf Stream and circulation at depth in DWBC. Using model experiments, Zhang and Vallis (2007) invoked bottom vortex stretching as the mechanism that explains the Gulf Stream position off the continental slope downstream of Cape Hatteras and suggested that the intensified DWBC plays a role in the Northern Recirculation Gyre onset. It is not among our objectives to revisit these results. Still, based on the numerous sensitivity experiments that we ran and the diagnostics of the intensity of bottom vortex stretching, we confirm that the improvement of both Gulf Stream and DWBC pathways in ERNA compared to ORCA_REF is not fortuitous.

\subsection{The Intergyre region}

The North Atlantic Inter-Gyre region is the transition between the subtropical and the subpolar gyres (Marshall et al., 2001), extending from the Grand Banks tail up to the North West Corner (NWC), from the western boundary to the east of the Mid-Atlantic Ridge.

Sea Surface Height observations show that downstream of Cape Hatteras, around $45^{\circ} \mathrm{W}-44^{\circ} \mathrm{N}$, the Gulf Stream current splits in two branches: one flows to the northeast Atlantic basin via the North Atlantic Current (NAC hereafter) through the NWC, and one joins the Worthington Gyre and the Azores current to the southeast (Fig. 5a). Such a bifurcation is well reproduced in ERNA where three troughs are clearly visible in the NAC pathways at $40^{\circ} \mathrm{N}, 44^{\circ} \mathrm{N}$ and $47^{\circ} \mathrm{N}$, which is in very good agreement with observations (Fig. 5b). The NAC northward extension in the NWC is also well reproduced in ERNA, as we can see on the velocities structures at the surface 
(Fig 6a). The eastward, almost zonal extension of the NAC centered around $50^{\circ} \mathrm{N}$ above the Mid-Atlantic Ridge is not as zonal in ERNA as observed, suggesting that the simulated subpolar gyre has an underestimated eastward extension. The NAC meandering structure is also visible in the EKE field, both in observations and ERNA with local maxima off the Grand Banks (Fig. 3).

The difference between ERNA and ORCA_REF is large in this region; in ORCA_REF the NAC flows further offshore, from the southeast of the Grand Banks to the Iceland basin without meandering off the Flemish Cap or forming a NWC (Fig. 5c, 6a and 6b). Hence the NAC moves to the northeast too far south of the Charlie Gibbs Fracture Zone which is associated with an overestimated southward extension of the subpolar gyre.

The NAC position strongly impacts thermohaline properties in the Intergyre region (Fig. 7). In ORCA_REF, the Sea Surface Temperature (SST) and the Sea Surface Salinity (SSS) exhibit large cold and fresh biases (Fig. $7 \mathrm{~b}, \mathrm{~d})$. Although these biases partly derive from a mismatch in scales between the simulation and climatology (which has an even coarser resolution), they are common to ocean models (Griffies et al., 2009), and hence to climate models. Weese and Bryan (2006) have shown, using a coupled model, that reducing those biases has a positive impact on the atmosphere and also suggests a potential impact on water masses at higher latitudes. These biases do not exist at all in ERNA, where surface anomalies are rather warm and salty (Fig. 7a,c). Temperature and salinity anomalies related to the wrong position of the NAC in ORCA_REF are also visible at depth, down to approximately $1000 \mathrm{~m}$. By contrast, the thermohaline profile in ERNA com- 
puted offshore of the Flemish cap (not shown) compares well with observed climatology.

The vertical structure of the current along the Grand Banks is compared to observations (Schott et al. (2006), their Fig.1b) at $43^{\circ} \mathrm{N}$; see Fig.1 for section location). ERNA (Fig. 8a) shows a position and extension at depth (down to the bottom) that compares well with observations. The ERNA NAC mean intensity of $55 \mathrm{~Sv}$ is weaker by at least a factor of 2 compared to the evaluation by Schott et al. (2006) of $142 \mathrm{~Sv}$, but is comparable to that obtained by Bryan et al. (2007) in their $1 / 10^{\circ}$ model. In ORCA_REF (Fig. 8b), as already noticed for the Gulf Stream, the NAC surface currents are much slower and cover a wider area. The DWBC vertical extension is limited to $2900 \mathrm{~m}$ depth only and does not show an intensification along the topographic slope as in ERNA. As will be discussed later, the main pathway of DWBC is indeed located to the west of Mid-Atlantic Ridge (Fig. 6d), which is not covered by the section in Fig. 8.

\subsection{The Subpolar Gyre}

In the Subpolar Gyre, heat carried from the subtropics by the NAC, the upper part of AMOC, is released to the atmosphere as intermediate and dense water is formed. This water incorporates into the DWBC, together with denser water masses overflowing through the sills between Greenland and Scotland (Dickson and Brown, 1994). The DWBC, which is the deep limb of AMOC, merges with the deep barotropic Subpolar Gyre in this region. Hence intercomparing the simulated Subpolar Gyre characteristics is 
relevant to our objective of understanding how model resolution affects the AMOC.

The Sea Surface Height structure and amplitude in the ERNA Subpolar Gyre are close to observations (Fig. 5a,b), in particular the extension of low sea level along Newfoundland down to the Grand Banks. In ORCA_REF, the Sea Surface Height structure is marked by its excessive southward extension due to the misrepresentation of NAC and NWC (Fig. 5c).

The maximum mean barotropic streamfunction $\psi_{\max }$ (not shown), measured in a box centered in Labrador Sea $\left[55^{\circ} \mathrm{W}-53^{\circ} \mathrm{W}\right.$ and $\left.56.5^{\circ} \mathrm{N}-58.5^{\circ} \mathrm{N}\right]$, is 36 Sv and $31 \mathrm{~Sv}$ in ERNA and ORCA_REF respectively. When considering the convective years of the mid 1990s only, the annual mean maximum in ERNA is in the range [43-45] $\mathrm{Sv}$ which is close to the $43 \mathrm{~Sv}$ reference value obtained in Treguier et al. (2005) for a set of high resolution simulations $\left[1 / 6^{\circ}-1 / 12^{\circ}\right]$, while in ORCA_REF it remains at $34 \mathrm{~Sv}$. In the Irminger Sea box $\left[42^{\circ} \mathrm{W}\right.$ $38^{\circ} \mathrm{W}$ and $\left.59^{\circ} \mathrm{N}-61^{\circ} \mathrm{N}\right], \psi_{\max }$ is $35 \mathrm{~Sv}$ in ERNA which is, again, comparable to the simulations of Treguier et al. (2005), while ORCA_REF reaches only $30 \mathrm{~Sv}$.

To further analyse the structure of currents in the Labrador Sea, we compared both experiments with repeated observations along the AR7W section (Fig. 9; see Fig. 1 for section location). The West Greenland Current, visible at the northern end of the AR7W section and the Labrador Current at the southern end flow cyclonically around the Labrador Sea. In ERNA, the barotropic structure of currents matches quite well that of the composite of Hall et al. (2013) (see their Fig 5a). Remarkable features arise in ERNA with anticyclonic recirculation cells offshore of both boundary currents, which 
have already been described in observations (Lavender et al., 2000; Hall et al., 2013). Note also that the West Greenland Current is tilted offshore at depth as found in observations, although the simulated tilt is underestimated. This is presumably due to the underestimation of the Denmark Strait Overflow Water in ERNA, which is also visible in the deep Labrador Current, a bias that is common to OGCM even at higher resolution (Treguier et al., 2005). In ORCA_REF, the boundary currents are weaker and broader than in ERNA and the interior recirculation cell is hardly visible.

Convective activity in the Labrador Sea, as illustrated by the winter (FebruaryApril) mixed layer depth (MLD), differs significantly between experiments with a deeper mixed layer over a larger area in ERNA than in ORCA_REF (Fig. 10, based on the $0.03 \mathrm{~kg} \mathrm{~m}^{-3}$ density criteria). In ERNA, contrary to ORCA_REF, deep winter mixed layers develop also in the narrow Labrador Current, consistent with observations of upper Labrador Sea Water formation (Pickart et al., 1997) and another high resolution model (Deshayes et al., 2007). Note that the presence of subtropical warm waters in the NWC contributes to limiting the southward extension of the negative convective patch in ERNA.

In the Irminger Sea, the mean winter MLD reaches $800 \mathrm{~m}$ depth to the southeast of Greenland in ERNA, a pattern apparently linked to the Labrador Sea convective patch which does not exist in ORCA_REF. Convection in the Irminger Sea is consistent with observations (Vage et al., 2011a, 2008; Pickart et al., 2003) and other simulations (Deshayes et al., 2007).

The climatology of observed winter MLD (de Boyer Montégut, 2004), updated to include ARGO float data to September 2008 on a $2^{\circ} \times 2^{\circ}$ grid resolu- 
tion) shows values hardly deeper than $400 \mathrm{~m}$ depth in the central Labrador Sea, suggesting that both simulations largely overestimate the mixed layer depth (it exceeds $2400 \mathrm{~m}$ and $1600 \mathrm{~m}$ in ERNA and ORCA_REF respectively).

It should be keept in mind that simulated mean values cover the period 1990-2009, different to the period of observation used for the climatology data (essentially ARGO data from 1995 to 2008). Still, it must be noted that winter MLD is overestimated in ERNA and ORCA_REF, a bias common to ocean hindcasts using NEMO (Rattan et al., 2010).

Although the winter mean MLD (Fig. 10a, b) over the period 1990-2009 seems lower in ORCA_REF than in ERNA, a monthly time series (not shown) of MLD, averaged in a box located in the central Labrador Sea, shows that this statement depends effectively on the period considered. During strong convective events in the early 1990s, the MLD is of the same order of magnitude in both experiments reaching deeper than $2500 \mathrm{~m}$. It is only in late the 1990s that the MLD is significantly lower in ORCA_REF than in ERNA. Our interpretation is that the spatial resolution in ERNA is not sufficient to reproduce the mesoscale restratification processes parameterized with GM in ORCA_REF. An additional low-resolution experiment (ORCA_NOG) without GM parameterization has been performed over the same period to illustrate the impact of GM on convection. The winter mean MLD is very similar in amplitude to ERNA, but it differs in shape (Fig. 10c). Hence spatial resolution in ERNA hardly affects the spatial structure of the convective patch in the subpolar gyre, despite at least partially resolving the mesoscale activity . Mesoscale restratification processes can be indirectly evaluated via 

421 overflow.

422 423

surface EKE. In ERNA, local maximum $\left(80 \mathrm{~cm}^{2} s^{-2}\right.$ contour $)$ arises north of $60^{\circ} \mathrm{N}$ and extends to the northwest along the Western Greenland Current (Fig. 11b). This pattern corresponds to a relatively shallower mixed layer (Fig. 10a). In observations it is shifted westward around $52^{\circ} \mathrm{W}$ and extends to the south. This structure is associated with eddies known as Irminger rings, which are important for restratification in the interior Labrador Sea (Chanut et al., 2008). Their mis-representation in ERNA largely contributes to the overestimated winter MLD. Irminger rings are related to a topographic feature near Cape Desolation with very close isobaths on the cross-shore direction (Katsman et al., 2004; Eden and Böning, 2002) which seems to require a representation of the bathymetry with an even higher resolution than the one of ERNA. Note that AVISO observations are not able to capture EKE activity beneath the sea-ice cover near the coast around the Irminger and Labrador Seas, so it is not possible to evaluate EKE local maxima in the coastal strip simulated in ERNA.

\subsection{The Nordic Seas}

Similarly to the subpolar gyre, the Nordic Seas receive heat from the subtropics via the NAC and release it to the atmosphere as dense water is formed. They are also the source region for water masses overflowing the Greenland-Scotland ridge, which constitute the densest components of the DWBC. Spatial resolution seems to affect both processes, convection and

As found in the Labrador Sea, the mean winter mixed layer depth is substantially deeper in ERNA compared to ORCA_REF and, again, exceeds 
observed climatology (Fig. 12). Nevertheless, the spatial structure of the convective patch is clearly more realistic in ERNA, centered around $75^{\circ} \mathrm{N}$, $0^{\circ} \mathrm{E}$, while it is located along the Norwegian coast in ORCA_REF. Simulation ORCA_NOG produces a mean winter MLD very similar to ORCA_REF, suggesting that convective processes are not well developed in both experiments in this area. As a result, it is likely that the location of the convective patch is improved in ERNA because the circulation and thermohaline properties are overall more realistic.

This notwithstanding, in ERNA the East Greeland Current is narrower and stronger than in ORCA_REF (observations are not available to make a direct comparison). This reduces the offshore extension of sea-ice, in particular in summer, which, in turn, induces large SST (up to $1^{\circ} \mathrm{C}$ ) and SSS (up to 1 PSU) anomalies near the sea-ice edge as the ocean fraction that is free of ice is directly exposed to radiative and turbulent fluxes. These anomalies are then progressively advected southward toward the Irminger and Labrador Seas where they contribute to a large-scale warm and salty bias. Hence, the increase in resolution in the Nordic Seas has both positive (the improvement of convection location) and negative (warm and salty bias in the subpolar gyre) consequences.

Evaluating the simulated Nordic Seas in detail is beyond the scope of this paper. Still, we speculate here what we describe in the next section, namely that the improvement of Nordic Seas dense water formation is consistent with the improvement of dense water overflow through the Denmark Strait in ERNA. 


\section{Impacts on the AMOC}

The Atlantic Meridional Overturning Circulation (AMOC) is a synthetic representation of the large-scale northward surface flow of warm and salty water and the deep southward return flow of cold and fresh water. In the following we analyse how regional improvements related to the $1 / 8^{\circ}$ nest impact the AMOC in underlining the role of dense water transported by the DWBC from the overflows downstream to mid-latitude. We follow on with a detailed analysis of the latitude dependence of the AMOC maximum, in both density and depth coordinates, to infer the upper ocean influence on the AMOC. Finally, we discuss and compare our findings with observations of the AMOC structure at $26.5^{\circ} \mathrm{N}$, near the southern boundary of the nest.

\subsection{Meridional overturning streamfunction}

We choose to represent the AMOC in $\sigma_{2}$ density space (Fig. 13) because it reveals the contribution of newly formed dense water masses better than the classical depth space AMOC. We ensured that the initial three-year spinup, although short, does not influence the following results through the maximum $\mathrm{AMOC}$ at $43^{\circ} \mathrm{N}$ time series (not shown).

The temporal mean AMOC maximum arises at high latitude close to the North Atlantic convective areas and reaches $24 \mathrm{~Sv}$ at $54^{\circ} \mathrm{N}$ and $17 \mathrm{~Sv}$ at $58^{\circ} \mathrm{N}$ in ERNA and ORCA_REF respectively. A second local AMOC maximum arises to the south in both experiments revealing again a $7 \mathrm{~Sv}$ difference between ERNA and ORCA_REF. These secondary maxima are located at the same latitude and have the same amplitude, namely $21 \mathrm{~Sv}$ and $14 \mathrm{~Sv}$ for ERNA and ORCA_REF respectively, as the AMOC maxima when calculated 
in depth space (not shown). This is consistent with previous studies comparing the AMOC in depth and density space (Danabasoglu et al., 2013; Zhang, 2010; Griffies et al., 2009), advocating the use of the latter representation for high latitudes AMOC investigations.

In ERNA the AMOC maximum is located in density layers close to 36.78 $\mathrm{kg} \mathrm{m}^{-3}$ at high latitude and $36.62 \mathrm{~kg} \mathrm{~m}^{-3}$ for the second maximum, while in ORCA_REF it is close to $36.52 \mathrm{~kg} \mathrm{~m}^{-3}$ at high latitude and $36.39 \mathrm{~kg} \mathrm{~m}^{-3}$ to the south. Hence water masses forming the deep limb of the AMOC are overall denser in ERNA than in ORCA_REF. This also suggests that these water masses tend to become lighter from $55^{\circ} \mathrm{N}$ southward. This is clearly visible in ERNA, where the overturning streamfunction contours for densities of $36.7-36.85 \mathrm{~kg} \mathrm{~m}^{-3}$ are oriented towards lower density at low latitude. Such trend is not obvious in ORCA_REF, where overturning streamfunction contours in the deep limb of AMOC are either flat or bending towards higher density at low latitude. The latter remains unexplained, although it seems to be a feature common to other ORCA $1 / 2^{\circ}$ simulations (Biastoch et al. 2008, their figure 1d).

In summary, the contrast in shape and intensity of the AMOC between both experiments is important. Here an increase in horizontal resolution results in a $7 \mathrm{~Sv}$ stronger AMOC. It also improves the circulation at the bottom, with a clearly defined deep AMOC limb. The question is where these differences come from, i.e. whether: an increased horizontal resolution is amplifying existing processes or whether there are new processes being represented ? We focus firstly on the deep limb of the AMOC, i.e. dense 
water transport by the DWBC, to answer this question.

\subsection{Deep Western Boundary Current}

The DWBC constitutes the AMOC deep limb exporting NADW equatorward (see Lozier 2012 for a review on AMOC). We hereafter analyse the DWBC transport and whenever possible compare it with direct observations along its pathways from the Denmark strait overflow down to Cape Hatteras. The total transport in the DWBC is computed for water masses denser than $27.68 \mathrm{~kg} \mathrm{~m} \mathrm{~m}^{-3}$. We also compute the transport of water masses denser than $27.80 \mathrm{~kg} \mathrm{~m} \mathrm{~m}^{-3}$ that characterizes the North East Atlantic Deep Water and the Denmark Strait Overflow Water masses. All transport calculations are bound onshore by topography and offshore by zero isotach.

We chose seven sections to monitor dense water transport in the DWBC: at its origin at the Denmark strait (section DSO), in the Irminger sea (sections IRM, upstream of the local convection site, and GRE near Cape Farewell), in the Labrador Sea (the south-western part of AR7, and section FIS studied by Fischer et al. 2010), near Grand Banks (section SCH studied by Schott et al. 2006) and finally near Cape Hatteras (section LIW along line W, http://www,whoi.edu/science/PO/linew/index.htm).

The DWBC total transport (Fig. 14a) and transport for densities greater than $27.80 \mathrm{~kg} \mathrm{~m}^{-3}$ (Fig. 14b) are systematically larger in ERNA than in ORCA_REF. They increase gradually from the Denmark strait down to the central Labrador Sea, then substantially decrease in the Inter-gyre region through FIS and SCH sections, and finally, in ERNA only, intensify again 
in the Northern Recirculation Gyre. In ORCA_REF, the DWBC transports at sections SCH and LIW almost vanish, as also indicated by cross-section velocities (Fig. 8b, 4c). As a result, both simulations differ in the intensity of DWBC transport, but also in their DWBC pathways through the Intergyre region. Below, we investigate each section in detail, contrasting both simulations and comparing them with observations.

At the Denmark strait, the dense DWBC transport (of water denser than $27.80 \mathrm{~kg} \mathrm{~m} \mathrm{~m}^{-3}$ ) is very close to observations in ERNA and $30 \%$ higher than in ORCA_REF, the difference reaching almost 1 Sv. The transport of water denser than $27.88 \mathrm{~kg} \mathrm{~m} m^{-3}$ reaches $2.4 \mathrm{~Sv}$ in ERNA against $1.3 \mathrm{~Sv}$ in ORCA_REF, which represents $75 \%$ and $54 \%$ of the dense transport (of water denser than $27.80 \mathrm{~kg} \mathrm{~m}^{-3}$ ) respectively. This suggests that water masses near sill depth are denser in ERNA than in ORCA_REF. Ultimately, the $27.80 \mathrm{~kg}$ $\mathrm{m}^{-3}$ isopycnal surface in GIN Seas (at about 100m depth) occupies a larger horizontal area and is located shallower in ERNA than in ORCA_REF, which facilitates the formation of denser water masses by convection.

Downstream of the Denmark Strait through the IRM section the total transport significantly increases in both experiments, reaching almost the same intensity. The dense DWBC transport is strongly reduced in ORCA_REF while it increases in ERNA due to the better resolved entrainement and to the presence of denser water at the Denmark Strait compared to ORCA_REF. We have noted the absence of North East Atlantic Deep Water flowing northward on the western flank of the Reykjanes Ridge in ERNA, 
which increases the relative contribution of Denmark Strait Overflow Waters in the DWBC, a clear bias in ERNA. The entrainment process is not perfectly resolved in ERNA either as there is no water denser than $27.88 \mathrm{~kg} \mathrm{~m} \mathrm{~m}^{-3}$ in the subpolar gyre, which is contrary to observations.

The total and dense water transports increase from IRM to GRE in both simulations, although to a larger extent in ERNA than in ORCAR_REF. This reflects the contribution of the Irminger Gyre (Vage et al., 2011a). In addition, in ERNA there is a clear export of LSW from the Labrador Sea to the Irminger Sea which then returns to the DWBC, consistent with observations (Lavender et al., 2000), which is not visible in ORCA_REF. Moreover, convection occurs in the Irminger Sea in ERNA (Fig. 10a) and forms water masses denser than $27.74 \mathrm{~kg} m^{-3}$ in the 1990s, which contributes to an increase in the dense transport through GRE.

The total DWBC transport is analysed in both experiments through section AR7. The simulated value in ERNA is very close to observations by Hall et al. (2013). In ORCA_REF it is 33\% smaller; this is to be attributed to a weaker transport upstream as described before, a lower level of dense water formation in the Labrador Sea, and also to the missing recirculation in the interior Labrador Sea (Lavender et al., 2000) that feeds back into the Labrador Current (Fig. 9). The dense transport is also much larger in ERNA than in ORCA_REF, because (i) the currents are stronger at depth in ERNA (Fig. 9 b), and (ii) 27.80 isopycnal is shallower in ERNA (around $1000 \mathrm{~m}$ depth) than in ORCA_REF (around $2500 \mathrm{~m}$ depth, blue contours in Fig. 9c). 
The latter is due to convection in ERNA that produces water masses denser than $27.80 \mathrm{~kg} \mathrm{~m}^{-3}$, which is clearly unrealistic. As a result, dense transport in ERNA is larger than the observations.

Observations across section FIS (Fischer et al., 2010) yield similar total transport but larger dense transport than through AR7 (Hall et al., 2013). As at AR7, total and dense water transports in ERNA compares well with FIS observations, while both transports are smaller in ORCA_REF.

Near the Grand Banks, in both experiments the $\mathrm{SCH}$ section shows the first strong reduction in total DWBC transport, although already initiated at the FIS section. This region is a key location for interaction between the DWBC and the NAC in ERNA, as suggested by observations (Bower et al., 2011; Kieke et al., 2009), with the circulation of upper Labrador Sea Water eastward along with the NAC downstream of Flemish Cap. Although both experiments show an important decrease in the DWBC transports, it is dramatic in ORCA_REF as there is no dense transport through SCH and hardly any total transport. Indeed, the main pathway for the DWBC in ORCA_REF is eastward at the exit of the subpolar gyre and then southward on both sides of the Mid-Atlantic Ridge, as found in the simulation described by Deshayes et al. (2007) (see Fig. 6d). In ORCA_REF, there is no interior pathway as described by Bower et al. (2009) and associated with a strong eddy activity eastward of the continental shelf between $40^{\circ} \mathrm{N}$ and $50^{\circ} \mathrm{N}$. The pathway along the Mid-Atlantic-Ridge arises in ERNA (Fig. 6c), but it is clearly of minor importance (similar as observations by Kieke et al. 2009), as 
the DWBC transport across section $\mathrm{SCH}$ is close to the AMOC strength at this latitude (20 Sv in density coordinates, and $17 \mathrm{~Sv}$ in depth coordinates). It also compares very well with observations, both for the total and for dense transport.

Observations of the circulation across Line W, located north of Cape Hatteras, exhibit the signature of the Northern Recirculation Gyre along with the DWBC at depth (Toole et al., 2011). As noted above, the Northern Recirculation Gyre does not exist in ORCA_REF, but it is well represented in ERNA (Fig. 4b). Accordingly, total and dense transport in ERNA compare well with observations, while there is hardly any southward transport through section LIW in ORCA_REF. Note that ERNA transports are actually overestimated, probably due to exaggerated recirculations along the DWBC within the Northern Recirculation Gyre.

In summary, the ERNA experiment is clearly different from ORCA_REF with a stronger DWBC representation all along the western boundary of the North Atlantic. At high latitudes the DWBC transport in ERNA increases gradually from the Denmark Strait, through entrainment downstream in the Irminger Sea and due to the convective process in both the Labrador and Irminger seas. All three processes are poorly simulated in ORCA_REF. In addition, recirculations along DWBC (in the Labrador Sea and the Northern Recirculation Gyre), well reproduced in ERNA only, strengthen the transports (in fact excessively so in the Northern Recirculation Gyre), which contributes to improving the comparison with observations. Finally, there is a 
clear bias in the pathway of the DWBC in the ORCA_REF Inter-gyre region, which affects all comparisons with observations further south of this region. As a result, DWBC transports in ERNA are comparable to observations, while transports in ORCA_REF are much smaller and even null south of Flemish Cap.

\subsection{Upper ocean influence on the $A M O C$}

When computing the AMOC in density coordinates (AMOC- $\sigma$ ), it is relatively straightforward to relate the DWBC transport with AMOC intensity. By contrast, the AMOC intensity in depth coordinates (AMOC-z) can not be directly related to the DWBC transport because of compensations in the horizontal that are actually indicative of the influence of upper ocean circulation on the AMOC. We explore both perspectives by investigating the latitudinal dependence of AMOC maximum, first in density and then in depth coordinates.

According to the DWBC transport in ERNA, the AMOC- $\sigma$ increases gradually southward from 5-6 Sv at $68^{\circ} \mathrm{N}$ (north of the Denmark Strait overflow), up to $24 \mathrm{~Sv}$ at $52^{\circ} \mathrm{N}$ (Fig. 15, black dashed line). This increase is due to entrainment and convective processes, as recirculations along DWBC do not contribute to intensify the AMOC (they nearly cancel out when averaging zonally). The AMOC maximum then decreases in the latitude band $52^{\circ}-42^{\circ} \mathrm{N}$ (vertical yellow stripe) which corresponds to the Inter-gyre region, suggesting intensified mixing in this latitude band, with lighter subtropical water masses transported by NAC. It finally stabilizes around $22 \mathrm{~Sv}$ at $35^{\circ} \mathrm{N}$, 
the secondary maximum of the overturning streamfunction (Fig. 13).

The picture emerging from ORCA_REF is very similar (Fig.15, red dashed line), except that each process strengthening AMOC is hindered, as has already been noted for DWBC transports. On the other hand, the decrease in AMOC in the Intergyre region is more important in ORCA_REF than in ERNA. This suggests that along its peculiar path east of Flemish Cap, NADW experiences more diapycnal mixing with surrounding lighter water masses. Actually, the cumulated southward transport of dense water masses from Flemish Cap eastward reveals that most of the AMOC deep limb is located on both sides of the Mid-Atlantic Ridge (not shown). This considerably lengthens the pathway of NADW from the Labrador Sea southward, hence increasing the amount of diapycnal mixing undergone along the route. Indeed, we observe a deepening of the isopycnal surface $\sigma_{2}=36.925 \mathrm{~kg} \mathrm{~m}^{-3}$ (at a mean rate of [10-20] $\mathrm{m}_{\text {year }}{ }^{-1}$ ) throughout the simulation, with the largest amplitude to the west of the Mid-Atlantic Ridge, in the latitude band that corresponds to the AMOC decrease (purple and yellow stripes), which corresponds to the mean pathway of the DWBC in ORCA_REF.

In calculations of the AMOC in depth coordinates, only one maximum appears at about $35^{\circ} \mathrm{N}$ in both simulations (Fig. 15, plain lines), as most of the (dense) southward flow in the subpolar gyre is compensated for by a (lighter) northward flow at the same depth. The latitudinal dependence of the AMOC maximum differs a lot among simulations. In ORCA_REF, the AMOC maximum increases almost linearly from the overflows (vertical 
cyan stripe) to $35^{\circ} \mathrm{N}$, reflecting both (i) the deepening of DWBC (as revealed by the overturning streamfunction in depth coordinates, not shown), and (ii) the uplifting of the penetration depth of the gyre circulation (from barotropic in the subpolar gyre to baroclinic in the subtropical gyre). By contrast, in ERNA there are two sharp increases in AMOC: at the latitudes of Flemish Cap (vertical yellow stripe) and Cape Hatteras (vertical pink stripe), where there are major interactions between the upper ocean circulation and the DWBC. At higher latitudes, the very close depth-coordinates AMOC in ERNA and ORCA_REF, despite the substantial difference in AMOC- $\sigma$, is consistent with previous studies (Danabasoglu et al., 2013; Zhang, 2010; Griffies et al., 2009) which support the claim that AMOC-z is not the proper way to investigate the NADW fraction associated with deep water formation.

At $35^{\circ} \mathrm{N}$, AMOC-z and AMOC- $\sigma$ have similar values (22 Sv in ERNA and $14 \mathrm{~Sv}$ in ORCA_REF). These are $2 \mathrm{~Sv}$ in ERNA and $4 \mathrm{~Sv}$ in ORCA_REF smaller than the maximum AMOC- $\sigma$ at higher latitude. Hence the difference between $\sigma$-and z-AMOC maxima is the smallest in ERNA, in which the NAC and the Gulf Stream interact with the DWBC. This suggests that the NADW formation rate alone does not set the amplitude of AMOC at mid-latitude, as the interaction with the upper ocean circulation plays a role as well.

South of $35^{\circ} \mathrm{N}$, AMOC- $\sigma$ and AMOC-z have similar values which are relatively stable in ORCA_REF while they decrease continuously in ERNA, suggesting that both upwelling and diapycnal mixing are very active in the 
northern part of the subtropical gyre in ERNA.

\section{4. $A M O C$ at the RAPID section}

Continuous observations along the RAPID section yield an unprecedented direct monitoring of the AMOC strength at $26.5^{\circ} \mathrm{N}$. The AMOC amplitude in ERNA, which is $18 \mathrm{~Sv}$ at this latitude, compares well with $17.3 \mathrm{~Sv}$ from observations (http://www.noc.soton.ac.uk/rapidmoc/), although the depthcumulated transport differs in the deep AMOC limb, the thickness of the simulated one being underestimated (Fig. 16a). Such a bias also exists in ORCA_REF, which in addition has a weak AMOC amplitude (about $13 \mathrm{~Sv}$ ). It is important to keep in mind that interannual variability in AMOC is substantial, based on observations (Cunningham et al., 2007) as well as modeling experiments (Biastoch et al., 2008), hence comparing AMOC amplitude averaged over different time periods (2004-2011 for RAPID data vs 1990-2009 for model simulations) may lead to significant differences. However, interannual variability cannot explain the large difference in AMOC strength between ERNA and ORCA_REF, associated with a $250 \mathrm{~m}$ shallower AMOC maximum depth in ERNA.

Finally, we compare the two simulated density structures at this latitude (Fig. 16b), averaged over the whole basin (blue line) and along the western boundary $\left(85^{\circ} \mathrm{W}-70^{\circ} \mathrm{W}\right.$, black line). Two patterns clearly emerge above and beneath $900 \mathrm{~m}$ depth. From $900 \mathrm{~m}$ down to $3000 \mathrm{~m}$ depth, ERNA is denser than ORCA_REF. This is particularly the case along the western boundary, suggesting a primary contribution from the NADW transported 
by the DWBC. Between $300 \mathrm{~m}$ and $900 \mathrm{~m}$ depth, ERNA is lighter than ORCA_REF along the western boundary, but this difference almost disappears when averaging it over the whole section, indicating that ERNA is denser than ORCA_REF in the eastern part of the basin. Both effects can be seen as changes in the thermocline depth (confirmed by temperature and salinity differences over the section, not shown) that is deeper to the west and shallower to the east of the basin in ERNA compared to ORCA_REF. It is expected that increasing spatial resolution intensifies horizontal fronts, but how this would project onto thermocline depth remains unclear. At the eastern part of the basin, thermocline uplifting is also due to a better representation of the Mediterranean overflow in ERNA (vertical sections not shown).

\section{Discussions}

This study shows how an increase in the resolution significantly impacts the North Atlantic circulation at surface and at depth. We now discuss these improvements and their impact on AMOC as it remains difficult, even at $1 / 80$ resolution, to represent some processes.

\subsection{Bathymetry and numerics}

The horizontal resolution increase is a major difference between the ORCA_REF and ERNA experiments, together with a few numerical changes. This increase allows the model to better reproduce the topographic constraint on currents that flow, for instance, over the continental rise as the DWBC. The topography impacts the behavior of currents in key regions such as the Grand 
Banks where the NAC and the DWBC cross, or off the Southwest Greenland coast where abrupt topographic changes contribute to the generation of eddies (Katsman et al., 2004). In addition, we also point out that improvements in the representation of boundary currents are related to numerical choices such as horizontal viscosity and momentum advection scheme which are known to impact dynamics in the North Atlantic.

\section{2. $D W B C$ assessment}

In order to assess the impact of improved western boundary current systems on the AMOC, we compare the transport in the DWBC through a few sections in ERNA, ORCA_REF and from observations. We acknowledge that we compare, in Fig.14, the simulated DWBC transport averaged over 19902009 with sparse and irregularly sampled observations. However, we are restricting the simulated mean values over the same years as observations does not significantly change the result. In particular, the transport of the densest water masses $\left(\sigma_{0}>27.8 \mathrm{~kg} \mathrm{~m}^{-3}\right)$ through the AR7 south-west end section is overestimated. This is due to an excessive transformation of surface water masses in the Labrador Sea similar to that detailed in Gulev et al. (2007). Those overly dense water masses formed in the Labrador Sea replace both the missing Denmark Strait Overflow Water and the Iceland Scotland Overflow Water in ERNA; this explains why the total DWBC transport in ERNA is close to observations. The DWBC transport in ERNA is then improved for incorrect reasons; we are currently investigating whether and how this affects the mechanisms of AMOC variability in ERNA. 


\subsection{Overflows}

Not surprisingly for a vertical Z-level model, overflows are not well resolved either in ERNA or in ORCA_REF. Nevertheless, dense water transport $\left(\sigma_{0}>27.80 \mathrm{~kg} \mathrm{~m}^{-3}\right)$ through the Denmark strait in ERNA is closer to observations than in ORCA_REF (Fig.14). A section showing normal velocities and isopycnals (not shown) reveals that this improvement is related to stronger southward currents as well as the presence of denser water masses in the range $\left[\sigma_{0}>27.80\right.$ and 27.88$] \mathrm{kg} \mathrm{m}^{-3}$. We show that convective activity has been enhanced in the Nordic Seas in ERNA compared to ORCA_REF, which increases dense water production in this density range.

\subsection{NAC short-cut}

From ORCA_REF to ERNA, the NAC circulation off Newfoundland has clearly improved, leading to more realistic water mass characteristics in the intergyre region at the surface (Fig.7a,b) and at depth. Nevertheless, it is also worth noting the existence of a NAC short-cut on the southeast side of the Subpolar Gyre that directly feeds the Irminger current with warm and salty water advected from the Subtropical Gyre. This feature and its baroclinic destabilization likely explain the overestimated EKE (exceeding $80 \mathrm{~cm}^{2} s^{-2}$ seen in Fig.11). It occupies a large area in the southeastern part of the Irminger Sea. This pattern, which also appeared in $1 / 12^{\circ}$ NEMO regional configurations (see Dussin and Treguier (2010), their Fig.1), develops rapidly after the beginning of the simulation (within a few years). We hypothesize that this pattern is a consequence of existing biases in water masses leading to a weaker vertical density gradient in the eastward flow (from the northwest corner). It then becomes more barotropic and thus more sensitive 
to the Reykjanes ridge tail topography which constrains the flow to follow planetary potential vorticity contours, oriented meridionaly in this area. This idea is supported by numerical experiments in Zhu et al. (2010) (their Fig.9): the NAC short-cut does not exist in a simulation using full spectral nudging on temperature and salinity while it appears when relaxing this forcing. As a consequence of this short-cut in ERNA, temperature and salinity biases (Fig.7a,c) remain in the North Atlantic at surface and at depth. Biases are even amplified very locally off the Greenland and the Labrador coasts with respect to ORCA_REF.

The salinization bias in particular is common to numerous configurations as illustrated by Treguier et al. (2005) when analysing four high resolution model spanning $\left[1 / 6^{\circ}-1 / 12^{\circ}\right]$. They suggest an advective origin and rule out surface forcing and vertical mixing which differed between models. Rattan et al. (2010) go further, emphasizing that the initial central Labrador Sea salinity drift (lasting for 10 years) is linked to misrepresented freshwater pathways on both sides of Greenland, and to overestimated transport of warm and salty water by the Irminger current. We found the same drift and adjustment time period in both ERNA and ORCA_REF, using either inter-annual or a repeated normal year forcing. Interestingly, following the suggestion of Rattan et al. (2010), we apply a very weak SSS restoring within a $400 \mathrm{~km}$ wide band offshore (so almost no salinity restoring is applied in the Subpolar Gyre) to avoid spurious weak Eastern Greenland Current freshwater transport, but it has no clear impact on this salinity drift either in ERNA or ORCA_REF. 


\subsection{Deep intergyre circulation}

The Intergyre surface circulation differs drastically between ERNA and ORCA_REF; this is also the case at depth. Indeed, in ORCA_REF almost all DWBC transport exiting the Labrador Sea is exported eastward from Flemish Cap. One fraction flows through the Charlie Gibbs Fracture Zone and then recirculates in the Subpolar Gyre, while the rest flows southward along both sides of the Mid-Atlantic Ridge. Observations reported in Kieke et al. (2009) suggest that such an interior pathway exists for NADW, but that the main southward core of NADW remains along the continental shelf in the intergyre region. In ORCA_REF, the interior pathway is predominant and almost no NADW flows across the SCH section. Spence et al. (2012) suggest that coarse resolution models $\left(1^{\circ}\right)$ using high viscosity values have difficulties representing interior pathways for NADW towards low latitudes. Perhaps because it employs relatively low viscosity, ORCA_REF is not affected by this issue. In ERNA, both pathways are visible but the DWBC path along the western continental shelf is, by far, predominant, in agreement with observations.

\subsection{Model-dependency of the results}

Increasing the horizontal resolution over the North Atlantic from $1 / 2^{\circ}$ to $1 / 8^{\circ}$ leads to a strong intensification of the time mean AMOC maximum in our experiments. It is noteworthy that this result contrasts with the one obtained by Hodson and Sutton (2012). Indeed, when using two coupled AOGCM with oceanic resolution $1^{\circ}$ and $1 / 3^{\circ}$, the time mean maximum AMOC intensities (over 70 years of integration) were $22 \mathrm{~Sv}$ and $20 \mathrm{~Sv}$ at 
Cape Hatteras respectively. Hence the AMOC of their $1^{\circ}$ ocean presents a higher intensity than the $1 / 2^{\circ}$ ORCA_REF (whose average is only $14 \mathrm{~Sv}$ and endures a weakening trend over 20 years), while their $1 / 3^{\circ}$ has a value of the same order as ERNA 1/8 . In Hodson and Sutton (2012), AMOC magnitudes arise concurrently with an overestimation (by nearly a factor 2 in the $1^{\circ}$ ocean configuration) of mean mass transports through both the Denmark and Iceland-Scotland straits compared to observations (Shaffrey et al., 2009). So the tendency to increase the mean AMOC as resolution increases, demonstrated in our forced model, may be hindered by compensating biases in coupled models. It is also important to keep in mind the resolution increase when performing experiments like the ones for this study and for those conducted by Hodson and Sutton (2012): their highest resolution remains insufficient to resolve mesoscale processes in the subpolar region or in the subtropical North Atlantic. Hence our results are not directly comparable to theirs, although the methodology may look similar.

\subsection{Impact of the nest outside its imprint}

The grid refinement over the north Atlantic uses a two-way nesting approach that allows information exchange from fine to coarse grids. Hence anomalies arise when comparing ERNA and ORCA_REF outside the nested area.

To the North of the nest, near FRAM strait, an intensified Western Svalbard Current transports more subtropical water northward, leading to warmer $\left(0.3^{\circ} \mathrm{C}\right)$ and saltier (0.1 PSU) water masses at 500 meter depth. These changes develop on annual time scale; hence a longer simulation is necessary 
to assert their overall impact on the Arctic heat budget, and hence thermohaline circulation and other changes rapidly appear immediatly after the beginning of the simulation. To the west of Svalbard, a strong local warming (up to $1^{\circ} \mathrm{C}$ ) appears at the surface; its origin remains unclear. At the same time, a large salinization patch (up to 0.4 PSU) arises along the northeast Greenland coast over the shelf. The latter seems to be due to an intensified northward coastal current in ERNA that transports relatively salty water masses from lower latitudes. Concurrently, we notice $1 \mathrm{~Sv}$ cyclonic anomaly in barotropic stream function around Greenland.

To the South of the nest, a large cooling pattern at 500 meter depth develops (reaching $-0.5^{\circ} \mathrm{C}$ at the end of the simulation) in ERNA compared to ORCA_REF over a large area of the South Atlantic basin (from the equator to $35^{\circ} \mathrm{S}$ ). It clearly reflects an oceanic adjustment through rapid (within the first year) Kelvin waves propagating southward along the American coast, followed by Rossby waves propagating westward (on an interannual timescale) from the African coast, consistent with the theoretical study of Johnson and Marshall (2002). The process that triggers initial Kelvin waves remains unclear, but it is without doubtl located within the nest and not present in ORCA_REF. As for the Arctic, ERNA should be integrated for much longer time periods in order to clarify the role of these anomalies in the South Atlantic and beyond.

Finally, differences in maximum AMOC between ERNA and ORCA_REF are visible far beyond the southern boundary of the nest. They increase progressively in time and reach after approximately 15 years, respectively $4.0 \mathrm{~Sv}, 3.2$ $\mathrm{Sv}$ and $2.8 \mathrm{~Sv}$ at the equator, $20^{\circ} \mathrm{S}$ and $40^{\circ} \mathrm{S}$. We cannot exclude that larger 
897 AMOC anomalies develop on a longer time scale, as thermohaline properties 898 are advected through the South Atlantic to the Southern Ocean. 


\section{Conclusion}

In this paper we determine the impact of horizontal resolution on the North Atlantic western current system and the AMOC, using two hindcast ocean simulations: ERNA (a $1 / 8^{\circ}$ grid refinement over the North Atlantic embedded in a global ORCA $1 / 2^{\circ}$ grid) and ORCA_REF (a global ORCA $1 / 2^{\circ}$ grid only) that have been integrated for 20 years using the same interannual forcing. The higher horizontal resolution clearly leads to large improvements in the Gulf Stream, North Atlantic Current and Deep Western Boundary Current mean pathways. We perform a detailed analysis of the DWBC behavior and show that it is stronger in ERNA than in ORCA_REF, both due to the formation of overly dense water in the Labrador and Irminger Seas and improved overflows. Besides, we describe substantial changes in the DWBC pathway between ERNA and ORCA_REF in the intergyre region. While in ORCA_REF, the DWBC pathway follows a dominant unrealistic interior route, while it hugs the continental rise in ERNA (with a secondary interior pathway in agreement with observations, Kieke et al. 2009). Improvements in amplitude and structures of both the upper and deep circulation all contribute to improving the mean AMOC.

When computing the AMOC in density space, which is more adapted to follow dense water mass transport, the AMOC shape and maximum intensity look very different. The first (second) AMOC maximum arising in the Subpolar Gyre (at low latitudes near Cape Hatteras) presents a stronger intensity in ERNA of $6 \mathrm{~Sv}$ (up to $8 \mathrm{~Sv}$ ) than in ORCA_REF. We point out an important process, setting the AMOC maximum in addition to overflows 
and convection through the interaction between the upper ocean circulation and the DWBC mainly near Flemish Cap and Cape Hatteras. This interaction seems to control the intensity of the second AMOC maximum at low latitudes. In ORCA_REF, the decrease of AMOC from the Subpolar to Subtropical latitudes is due to the dominant DWBC interior pathway which does not allow for a proper interaction with NAC and enhances diapycnal mixing of NADW with surrounding lighter water masses, hence the subsequent AMOC decrease. Following Hodson and Sutton (2012), density anomalies linked to deep water formation in high latitudes propagate along the DWBC down to the subtropics, therefore a biased DWBC interior pathway as simulated in ORCA_REF may potentially affect the AMOC adjustment to high latitude perturbations, hence its variability. In this framework it would be interesting to extend this analysis to other low resolution ocean models that tend to underestimate the AMOC as illustrated in Griffies et al. (2009). The relative low AMOC intensities [ $4-14 \mathrm{~Sv}$ at $45^{\circ} \mathrm{N}$ ] may be partly due to the DWBC behavior in the intergyre region as illustrated in ORCA_REF.

Despite the numerous improvements highlighted in the ERNA experiment, limited salinity and temperature biases remain especially in the subpolar gyre where mesoscale processes are not correctly reproduced and further resolution increase or specific parameterizations for fine scale processes may be needed. These biases tend to be amplified as resolution increases, which may be due to a positive feedback from sea-ice in the Nordic Seas.

Due to the two-way nesting, consequences of the increased resolution and 
associated circulation changes are generated outside the nest boundaries, and these are noticeable. For instance, differences in the AMOC maximum in the North Atlantic propagate into most of the Southern Atlantic and reach almost $3 \mathrm{~Sv}$ at $40^{\circ} \mathrm{S}$ at the end of the simulation. Thus we anticipate significant changes in the Southern Ocean circulation for longer integrations in ERNA. The same is true for the Arctic Ocean, where substantial changes are already visible, in particular around Greenland. Thus for local and global reasons and because the North Atlantic exerts such an important role in water mass formation, we believe that this configuration could be a good alternative to global high resolution configurations in ocean-only mode as well as coupled to an atmospheric model. 
Acknowledgments. We are grateful to R. Curry, M. Hall and D. Torres for providing ready-to-use observations of the circulation across AR7W and Line W; to G. Garric for his advice when preparing the atmospheric forcing dataset ; to M. Vancoppenolle and P. Mathiot for their help on the sea-ice model; and to all contributors to the DRAKKAR consortium from which this work has benefited a great deal. For the analysis of simulated transports through DWBC sections, PAGO tools were used (http://www.whoi.edu/science/PO/pago).

Simulations have been realized using HPC resources from GENCI-IDRIS (Grant 2012-i2013012202). This work was funded by the European Commission's 7th Framework Programme, under Grant Agreement number 282672, EMBRACE project. We also acknowledge the three anonymous reviewers for their helpful comments.

\section{References}

Barnier, B., Madec, G., Penduff, T., Molines, J.M., Treguier, A.M., Sommer, J., Beckmann, A., Biastoch, A., Böning, C., Dengg, J., Derval, C., Durand, E., Gulev, S., Remy, E., Talandier, C., Theetten, S., Maltrud, M., McClean, J., Cuevas, B.. Impact of partial steps and momentum advection schemes in a global ocean circulation model at eddy-permitting resolution. Ocean Dynamics 2006;56(5-6):543-567. URL: http://www. springerlink.com/index/ 10.1007/s10236-006-0082-1. doi:10.1007/s10236-006-0082-1.

Benshila, R., Durand, F., Masson, S., Bourdall-Badie, R., de Boyer Montgut, C., Papa, F., Madec, G.. The upper 
bay of bengal salinity structure in a high-resolution model. Ocean Modelling 2013;(0):-. URL: http://www.sciencedirect.com/science/ article/pii/S1463500313002059. doi:http://dx.doi.org/10.1016/j. ocemod.2013.12.001.

Biastoch, A., Böning, C.W., Getzlaff, J., Molines, J.M., Madec, G.. Causes of InterannualDecadal Variability in the Meridional Overturning Circulation of the Midlatitude North Atlantic Ocean. Journal of Climate 2008;21(24):6599-6615. URL: http://journals.ametsoc.org/doi/abs/ 10.1175/2008JCLI2404.1. doi:10.1175/2008JCLI2404 . 1.

Blanke, B., Delecluse, P.. Low frequency variability of the tropical atlantic ocean simulated by a general circulation model with mixed layer physics. Journal of Physical Oceanography 1993;23:1363-1388.

Bower, A., Lozier, S., Gary, S.. Export of Labrador Sea Water from the subpolar North Atlantic: A Lagrangian perspective. Deep Sea Research Part II: Topical Studies in Oceanography 2011;58(1718):1798-1818. URL: http://linkinghub.elsevier.com/retrieve/ pii/S0967064511000233. doi:10.1016/j.dsr2.2010.10.060.

Bower, A.S., Lozier, M.S., Gary, S.F., Böning, C.W.. Interior pathways of the North Atlantic meridional overturning circulation. Nature 2009;459(7244):243-7. URL: http://www.ncbi.nlm.nih.gov/pubmed/ 19444214. doi:10.1038/nature07979.

Bower, S., Hunt, H.. Lagrangian Observations of the Deep Western Boundary Current in the North Atlantic Ocean . Part II : The Gulf Stream Deep 
Western Boundary Current Crossover *. Journal of Physical Oceanography 2000;(1990):784-804.

Brodeau, L., Barnier, B., Treguier, A.M., Penduff, T., Gulev, S.. An ERA40-based atmospheric forcing for global ocean circulation models. Ocean Modelling 2010;31(3-4):88-104. URL: http:// linkinghub.elsevier.com/retrieve/pii/S1463500309002017. doi:10. 1016/j.ocemod.2009.10.005.

Bryan, F.O., Hecht, M.W., Smith, R.D.. Resolution convergence and sensitivity studies with North Atlantic circulation models. Part I: The western boundary current system. Ocean Modelling 2007;16(34):141-159. URL: http://linkinghub.elsevier.com/retrieve/pii/ S1463500306000904. doi:10.1016/j.ocemod.2006.08.005.

Burchard, H.. Energy-conserving discretisation of turbulent shear and buoyancy production. Ocean Modelling 2002;4(34):347 361. URL: http://wWW.sciencedirect.com/science/article/pii/ S1463500302000094. doi:http://dx.doi.org/10.1016/S1463-5003(02) 00009-4.

Chanut, J., Barnier, B., Large, W., Debreu, L., Penduff, T., Molines, J.M., Mathiot, P.. Mesoscale Eddies in the Labrador Sea and Their Contribution to Convection and Restratification. Journal of Physical Oceanography 2008;38(8):1617-1643. URL: http://journals . ametsoc.org/doi/ abs/10.1175/2008JP03485.1. doi:10.1175/2008JP03485.1.

Chassignet, E.P., Garraffo, Z.D.. Viscosity parameterization and the Gulf 
stream separation. In: From Stirring to Mix- ing in a Stratified Ocean: Proc. Aha Hulikoa Hawaiian Win- ter Workshop, Honolulu, HI, University of Hawaii at Manoa,. 2001. p. 37-41.

Coetlogon, D., Frankignoul, C., Bentsen, M.. Gulf Stream Variability in Five Oceanic General Circulation Models. Journal of Physical Oceanography 2006;36:2119-2135.

Cunningham, S.a., Kanzow, T., Rayner, D., Baringer, M.O., Johns, W.E., Marotzke, J., Longworth, H.R., Grant, E.M., Hirschi, J.J.M., Beal, L.M., Meinen, C.S., Bryden, H.L.. Temporal variability of the Atlantic meridional overturning circulation at 26.5 degrees N. Science (New York, NY) 2007;317(5840):935-8. URL: http://www.ncbi.nlm.nih.gov/ pubmed/17702940. doi:10.1126/science.1141304.

Danabasoglu, G., Yeager, S.G., Bailey, D., Behrens, E., Bi, D., Biastoch, A., Bozec, A., Cassou, C., Chassignet, E., Danilov, S., Diansky, N., Farneti, R., Fernandez, E., Fogli, P.G., Forget, G., Gusev, A., Heimbach, P., Howard, A., Griffies, S.M., Kelley, M., Large, W.G., Leboissetier, A., Lu, J., Marsland, S.J., Masina, S., Navarra, A., George, A.J., Samuels, B.L., Scheinert, M., Terray, L., Treguier, A.m., Tsujino, H., Valcke, S., Voldoire, A., Wang, Q.. North Atlantic Simulations in Coordinated Ocean-ice Reference Experiments phase II ( CORE-II ). Part I : Mean. Ocean Modelling 2013;.

de Boyer Montégut, C.. Mixed layer depth over the global ocean: An examination of profile data and a profile-based climatology. Journal of Geophys- 
ical Research 2004;109(C12):C12003. URL: http://www.agu.org/pubs/ crossref/2004/2004JC002378.shtml. doi:10 .1029/2004JC002378.

Debreu, L., Vouland, C., Blayo, E.. AGRIF: Adaptive grid refinement in Fortran. Computers \& Geosciences 2008;34(1):8-13. URL: http:// linkinghub.elsevier.com/retrieve/pii/S009830040700115X. doi:10. $1016 /$ j.cageo. 2007.01 .009 .

Deshayes, J., Frankignoul, C., Drange, H.. Formation and export of deep water in the Labrador and Irminger Seas in a GCM. Deep Sea Research Part I: Oceanographic Research Papers 2007;54(4):510-532. URL: http: // linkinghub.elsevier.com/retrieve/pii/S0967063707000039. doi:10. $1016 / j . d s r .2006 .12 .014$.

Dickson, R., Brown, J.. The production of North Atlantic Deep Water: Sources, rates, and pathways. Journal of Geophysical Research 1994;99(C6):12319-12341.

Ducet, N., Le Traon, P.Y., Reverdin, G.. Global high-resolution mapping of ocean circulation from TOPEX/Poseidon and ERS-1 and -2. Journal of Geophysical Research 2000;105(C8):19477. URL: http:// www.agu.org/pubs/crossref/2000/2000JC900063.shtml. doi:10.1029/ $2000 J C 900063$.

Dussin, R., Treguier, A.M.. Evaluation of the NATL12-BRD81 simulation. Technical Report; 2010. URL: http://www.drakkar-ocean.eu/ publications/reports. 
Eden, C., Böning, C.. Sources of Eddy Kinetic Energy in the Labrador Sea. Journal of Physical Oceanography 2002;32(12):3346-3363. URL: http://journals.ametsoc.org/doi/abs/10.1175/1520-0485(2002) 032〈3346 : SOEKEI $\rangle 2$. 0. C0; 2 . doi:10.1175/1520-0485(2002)032/3346: SOEKEI $>2.0 . \mathrm{CO} ; 2$.

Ezer, T.. On the interaction between the Gulf stream and the New England Seamount chain. Journal of Physical Oceanography 1994;24.

Fischer, J., Visbeck, M., Zantopp, R., Nunes, N.. Interannual to decadal variability of outflow from the Labrador Sea. Geophysical Research Letters 2010;37(24):L24610. URL: http://www.agu.org/pubs/crossref/2010/ 2010GL045321. shtml. doi:10 . 1029/2010GL045321.

Fox-Kemper, B., Ferrari, R.. Parameterization of Mixed Layer Eddies. Part II: Prognosis and Impact. Journal of Physical Oceanography 2008;38(6):1166-1179. URL: http://journals.ametsoc.org/doi/abs/ 10.1175/2007 JP03788. 1. doi:10 .1175/2007JP03788 . 1.

Gnanadesikan, A., Griffies, S.M., Samuels, B.L.. Effects in a climate model of slope tapering in neutral physics schemes. Ocean Modelling 2007;16(1-2):1-16. URL: http://linkinghub.elsevier.com/retrieve/ pii/S1463500306000679. doi:10.1016/j.ocemod.2006.06.004.

Griffies, S.M., Biastoch, A., Böning, C., Bryan, F., Danabasoglu, G., Chassignet, E.P., England, M.H., Gerdes, R., Haak, H., Hallberg, R.W., Hazeleger, W., Jungclaus, J., Large, W.G., Madec, G., Pirani, A., Samuels, B.L., Scheinert, M., Gupta, A.S., Severijns, C.a., 
Simmons, H.L., Treguier, A.M., Winton, M., Yeager, S., Yin, J.. Coordinated Ocean-ice Reference Experiments (COREs). Ocean Modelling 2009;26(1-2):1-46. URL: http://linkinghub.elsevier.com/retrieve/ pii/S1463500308001182. doi:10.1016/j . ocemod.2008.08.007.

Gulev, S.K., Barnier, B., Molines, J.M., Penduff, T., Chanut, J.. Impact of spatial resolution on simulated surface water mass transformations in the Atlantic. Ocean Modelling 2007;19(3-4):138-160. URL: http:// linkinghub.elsevier.com/retrieve/pii/S1463500307000960. doi:10. 1016/j.ocemod.2007.07.004.

Hall, M.M., Torres, D.J., Yashayaev, I.. Absolute velocity along the AR7W section in the Labrador Sea. Deep Sea Research Part I: Oceanographic Research Papers 2013;72:72-87. URL: http://linkinghub.elsevier.com/ retrieve/pii/S0967063712002257. doi:10.1016/j.dsr.2012.11.005.

Herbaut, C., Sirven, J., Deshayes, J.. Sensitivity of the meridional transport in a 1 . 5-layer ocean model to localized mass sources. Journal of Marine Research 2006;64(1987):819-833.

Hodson, D.L.R., Sutton, R.T.. The impact of resolution on the adjustment and decadal variability of the Atlantic meridional overturning circulation in a coupled climate model. Climate Dynamics 2012;URL: http://www . springerlink.com/index/10.1007/s00382-012-1309-0. doi:10.1007/ s00382-012-1309-0.

Hsieh, W.. The free Kelvin Wave in Finite-Difference Numerical Models. Journal of Physical Oceanography 1983;. 
Johnson, H., Marshall, D.P.. A Theory for the Surface Atlantic Response to Thermohaline Variability. Journal of Physical Oceanography 2002;32:1121-1132.

Katsman, C.A., Spall, M.A., Pickart, R.S.. Boundary Current Eddies and Their Role in the Restratification of the Labrador Sea *. Journal of Physical Oceanography 2004;34:1967-1983.

Kieke, D., Klein, B., Stramma, L., Rhein, M., Koltermann, K.P.. Variability and propagation of Labrador Sea Water in the southern subpolar North Atlantic. Deep Sea Research Part I: Oceanographic Research Papers 2009;56(10):1656-1674. URL: http://linkinghub.elsevier.com/ retrieve/pii/S0967063709001058. doi:10.1016/j.dsr.2009.05.010.

Large, W.G., Yeager, S.G.. The global climatology of an interannually varying airsea flux data set. Climate Dynamics 2008;33(2-3):341364. URL: http://link.springer.com/10.1007/s00382-008-0441-3. doi:10.1007/s00382-008-0441-3.

Large and Yeager, S.G.. Diurnal to Decadal Global Forcing for Ocean and Sea-Ice Models: the Data Sets and Flux Climatologies. 2004;.

Lavender, K., Davis, R., Owens, W.. Mid-depth recirculation observed in the interior Labrador and Irminger seas by direct velocity measurements. Nature 2000;407(6800):66-9. URL: http://www.ncbi.nlm.nih. gov/pubmed/10993072. doi:10.1038/35024048.

Le Sommer, J., Penduff, T., Theetten, S., Madec, G., Barnier, B.. How momentum advection schemes influence current- 
topography interactions at eddy permitting resolution. Ocean Modelling 2009;29(1):1-14. URL: http://linkinghub.elsevier.com/retrieve/ pii/S1463500308001753. doi:10.1016/j.ocemod.2008.11.007.

Lozier, M.S.. Overturning in the North Atlantic. Annual Review of Marine Science 2012;4(1):291-315. URL: http://www.annualreviews . org/doi/abs/10.1146/annurev-marine-120710-100740. doi:10.1146/ annurev-marine-120710-100740.

Madec, G.. "NEMO ocean engine". Technical Report; Note du Pole de modélisation, Institut Pierre-Simon Laplace (IPSL), France, No 27 ISSN No 1288-1619; 2008.

Marsaleix, P., Auclair, F., Floor, J.W., Herrmann, M.J., Estournel, C., Pairaud, I., Ulses, C.. Energy conservation issues in sigmacoordinate free-surface ocean models. Ocean Modelling 2008;20(1):61 - 89. URL: http://www.sciencedirect.com/science/article/pii/ S1463500307000984. doi:http://dx.doi.org/10.1016/j.ocemod. 2007. 07.005 .

Marshall, J., Johnson, H., Goodman, J.. A Study of the Interaction of the North Atlantic Oscillation with Ocean Circulation. Journal of Climate 2001;14(7):1399-1421. URL: http://journals.ametsoc.org/doi/abs/ 10. 1175/1520-0442\%282001\%29014\%3C1399\%3AASOTIO\%3E2. 0. CO\%3B2. doi:10.1175/1520-0442(2001)014〈1399:ASOTIO〉2.0.CO; 2.

Mellor, G., Blumberg, A.. Wave Breaking and Ocean Surface Layer Thermal Response. Journal of Physical Oceanography 2004;34:693-698. 
Penduff, T., Le Sommer, J., Barnier, B., Treguier, A.M., Molines, J.M., Madec, G.. Influence of numerical schemes on current-topography interactions in 1 / 4 global ocean simulations. Ocean Science 2007;:509-524.

Pickart, R.S., Spall, M.a., Lazier, J.R.. Mid-depth ventilation in the western boundary current system of the sub-polar gyre. Deep Sea Research Part I: Oceanographic Research Papers 1997;44(6):1025-1054. URL: http:// linkinghub.elsevier.com/retrieve/pii/S0967063796001227. doi:10. 1016/S0967-0637(96)00122-7.

Pickart, R.S., Straneo, F., Moore, G.. Is Labrador Sea Water formed in the Irminger basin? Deep Sea Research Part I: Oceanographic Research Papers 2003;50(1):23-52. URL: http://linkinghub.elsevier.com/retrieve/ pii/S0967063702001346. doi:10.1016/S0967-0637(02)00134-6.

Rattan, S., Myers, P.G., Treguier, A.M., Theetten, S., Biastoch, A., Böning, C.. Towards an understanding of Labrador Sea salinity drift in eddy-permitting simulations. Ocean Modelling 2010;35(12):77-88. URL: http://linkinghub.elsevier.com/retrieve/pii/ S1463500310001009. doi:10.1016/j.ocemod.2010.06.007.

Roullet, G., Madec, G.. Salt conservation, free surface, and varying levels: a new formulation for ocean general circulation models. Journal of Geophysical Research 2000;105:23,927-23,942.

Schott, F.a., Fischer, J., Dengler, M., Zantopp, R.. Variability of the Deep Western Boundary Current east of the Grand Banks. Geophysi- 
cal Research Letters 2006;33(21):3-7. URL: http://www.agu.org/pubs/ crossref/2006/2006GL026563. shtml. doi:10.1029/2006GL026563.

Shaffrey, L.C., Stevens, I., Norton, W.a., Roberts, M.J., Vidale, P.L., Harle, J.D., Jrrar, a., Stevens, D.P., Woodage, M.J., Demory, M.E., Donners, J., Clark, D.B., Clayton, a., Cole, J.W., Wilson, S.S., Connolley, W.M., Davies, T.M., Iwi, a.M., Johns, T.C., King, J.C., New, a.L., Slingo, J.M., Slingo, a., Steenman-Clark, L., Martin, G.M.. U.K. HiGEM: The New U.K. High-Resolution Global Environment ModelModel Description and Basic Evaluation. Journal of Climate 2009;22(8):1861-1896. URL: http://journals.ametsoc.org/doi/abs/ 10.1175/2008JCLI2508.1. doi:10.1175/2008JCLI2508. 1.

Smith, R.D., Maltrud, M.E., Bryan, F.O., Hecht, M.W.. Numerical Simulation of the North Atlantic Ocean at 1 10. Journal of Physical Oceanography 2000;:1532-1561.

Spall, M.A.. Dynamics of the Gulf Stream/Deep Western Boundary Current Crossover. Part II: Low-Frequency Internal Oscillations. Journal of Physical Oceanography 1996;26:2169-2182.

Spence, P., Saenko, O.a., Sijp, W., England, M.. The Role of Bottom Pressure Torques on the Interior Pathways of North Atlantic Deep Water. Journal of Physical Oceanography 2012;42(1):110-125. URL: http://journals . ametsoc .org/doi/abs/10 .1175/2011JP04584. 1. doi:10.1175/2011JP04584.1.

Srokosz, M., Baringer, M., Bryden, H., Cunningham, S., Delworth, 
T., Lozier, S., Marotzke, J., Sutton, R.. Past, Present, and future changes in the Atlantic Meridional Overturning Circulation. Bulletin of the American Meteorological Society 2012;93(11):1663-1676. doi:10.1175/ BaMs-d-11-00151.1.

Toole, J.M., Curry, R.G., Joyce, T.M., Mccartney, M., Pen, B.. Transport of the North Atlantic Deep Western Boundary Current. Deep-Sea Research 2011;58:1768-1780. doi:10.1016/j.dsr2.2010.10.058.

Treguier, A.M., Theetten, S., Chassignet, E.P., Penduff, T., Smith, R.D., Talley, L.D., Beisman, J., Boning, C.W.. The North Atlantic Subpolar Gyre in Four High-Resolution Models. Journal of Physical Oceanography 2005;(2002):757-774.

Vage, K., Pickart, R.S., Moore, G.W.K., Ribergaard, M.H.. Winter Mixed Layer Development in the Central Irminger Sea: The Effect of Strong, Intermittent Wind Events. Journal of Physical Oceanography 2008;38(3):541-565. URL: http://journals . ametsoc . org/doi/abs/10. 1175/2007JP03678.1. doi:10.1175/2007JP03678.1.

Vage, K., Pickart, R.S., Sarafanov, A., Knutsen, O.y., Mercier, H., Lherminier, P., van Aken, H.M., Meincke, J., Quadfasel, D., Bacon, S.. The Irminger Gyre: Circulation, convection, and interannual variability. Deep Sea Research Part I: Oceanographic Research Papers 2011a;58(5):590-614. URL: http://linkinghub.elsevier.com/ retrieve/pii/S0967063711000562. doi:10.1016/j.dsr.2011.03.001.

Vage, K., Pickart, R.S., Spall, M.A., Valdimarsson, H., Jónsson, S., 
Torres, D.J., Ø sterhus, S., Eldevik, T.. Significant role of the North Icelandic Jet in the formation of Denmark Strait overflow water. Nature Geosciences 2011b;4(October). doi:10.1038/NGE01234.

Weese, S.R., Bryan, F.O.. Climate impacts of systematic errors in the simulation of the path of the North Atlantic Current. Geophysical Research Letters 2006;33(19):1-6. URL: http://www.agu.org/pubs/crossref/2006/ 2006GL027669.shtml. doi:10 .1029/2006GL027669.

Zhang, R.. Latitudinal dependence of Atlantic meridional overturning circulation (AMOC) variations. Geophysical Research Letters 2010;37(16):16. URL: http://www .agu.org/pubs/crossref/2010/2010GL044474. shtml. doi:10.1029/2010GL044474.

Zhang, R., Vallis, G.K.. The Role of Bottom Vortex Stretching on the Path of the North Atlantic Western Boundary Current and on the Northern Recirculation Gyre. Journal of Physical Oceanography 2007;37(8):2053-2080. URL: http://journals.ametsoc.org/doi/abs/ 10.1175/JP03102.1. doi:10.1175/JP03102.1.

Zhu, J., Demirov, E., Dupont, F., Wright, D.. Eddy-permitting simulations of the sub-polar North Atlantic: impact of the model bias on water mass properties and circulation. Ocean Dynamics 2010;60(5):1177-1192. URL: http://www. springerlink.com/index/10. 1007/s10236-010-0320-4. doi:10.1007/s10236-010-0320-4. 
1271

\section{List of figures}

Fig.1: Area covered by the $1 / 8^{\circ}$ nest over the North Atlantic in ERNA configuration, with a schematic location of major western boundary currents at the surface (red thick line) and at depth (blue thick line). Thin blue lines represent vertical sections location; LIW refers to "LineW" (Toole et al., 2011); SCH refers to Schott et al. (2006) section at $43^{\circ} \mathrm{N}$; FIS refers to Fischer et al. (2010) section at $53^{\circ} \mathrm{N}$; AR7 refers to the AR7W section in the Labrador Sea (Hall et al., 2013) and the DSO section through the Denmark Strait overflow (Vage et al., 2011b).

Fig.2: Position of the Gulf Stream as indicated by the $17^{\circ} \mathrm{C}$ isotherm at $177 \mathrm{~m}$ depth, averaged over the period 1990-2009, in simulations and observed climatology. Isobath contours [1000, 2000, 3000, 4000, 5000] m are drawn in thin grey lines.

Fig.3: Eddy Kintetic Energy (EKE) averaged over the period 1993-2009 in AVISO observations (a) and ERNA (b) in $\mathrm{cm}^{2} s^{-2}$.

Fig.4 Cross section velocities $\left(\mathrm{cm} \mathrm{s}^{-1}\right.$, C.I $\left.5 \mathrm{~cm} \mathrm{~s}^{-1}\right)$ through Line W (located on Fig. 1), in observations (a), ERNA (b) and ORCA_REF (c) with overlaid $\sigma_{0}$ isopycnals (blue contours density in $\mathrm{kg} \mathrm{m}^{-3}$ ). Observations are an average from all occupations of LineW, while simulation outputs are averaged over the period 1990-2009.

Fig.5: Sea Surface Height (SSH) averaged over the period 1993-2009 in 
AVISO observations (a), ERNA (b) and ORCA_REF (c). Contour interval is $5 \mathrm{~cm}$, and thick lines represent 0 contour.

Fig.6: Velocity fields in ERNA (a,c) and ORCA_REF (b,d) at the surface (top panels) and at $1511 \mathrm{~m}$ depth (bottom panels), averaged over the years 1990-2009. The background color corresponds to the modulus of velocity. Currents larger than $10 \mathrm{~cm} \mathrm{~s}^{-1}$ at the surface and $5 \mathrm{~cm} \mathrm{~s}^{-1}$ at depth are rescaled to the respective current speed threshold and shown in green.

Fig.7: Sea Surface Temperature (SST) (a,b) and Sea Surface Salinity (SSS) (c,d) anomalies to observed Levitus climatology (in ${ }^{\circ} \mathrm{C}$ and PSU) in ERNA (a,c) and ORCA_REF (b,d), averaged over the period 1990-2009.

Fig.8: Cross section velocities $\left(\mathrm{cm} \mathrm{s}^{-1}\right.$, C.I $5 \mathrm{~cm} \mathrm{~s}^{-1}$ ) through $\mathrm{SCH}$ (located on Fig. 1), in ERNA (a) and ORCA_REF (b) with overlaid $\sigma_{0}$ isopycnals (blue contours density in $\mathrm{kg} \mathrm{m}^{-3}$ ). Simulation outputs are averaged over the period 1990-2009.

Fig.9: Same as Fig. 4 for section AR7. Observations are composites of repeated measurements [1995-1996-1998-2001-2003-2008] (Hall et al., 2013).

Fig.10: Winter (February-April) Mixed Layer Depth (m) over the period 1990-2009 in the Labrador and Irminger Seas in ERNA (a), ORCA_REF (b) and ORCA_NOG (c). Black contours represent (de Boyer Montégut, 2004) climatology. 
Fig.11: Eddy Kintetic Energy (EKE) averaged over the period 1993-2009 in AVISO observations (a) and ERNA (b) in $\mathrm{cm}^{2} s^{-2}$.

Fig.12: Winter (February-April) Mixed Layer Depth (m) over the period 1990-2009 in Nordic Seas in ERNA (a), ORCA_REF (b) and ORCA_NOG (c). Black contours represent (de Boyer Montégut, 2004) climatology.

Fig.13: AMOC in $\sigma_{2}$ coordinates averaged over the period 1990-2009 in ERNA (a) and ORCA_REF (b). Contour interval is 2 Sv. Vertical Green dashed line locates the south boundary of the nest.

Fig.14: DWBC transport for $\sigma_{0}>27.68 \mathrm{kgm}^{-3}$ (a) and $\sigma_{0}>27.80 \mathrm{kgm} m^{-3}$ (b) through sections indicated in Fig.1 (whiskers indicating standard deviation). Observations are taken from Vage et al. (2011a) for DSO, Hall et al. (2013) for AR7, Fischer et al. (2010) for FIS, Schott et al. (2006) for SCH, Toole et al. (2011) for LIW.

Fig.15: ERNA (black) and ORCA_REF(red) AMOC maximum at each latitude calculated in depth (solid lines) and density ( $\sigma_{2}$, dash lines) space over the period 1990-2009. Shaded color bands are used in the text for clarity.

Fig.16: Thermohaline and circulation characteristics at $26.5^{\circ} \mathrm{N}$ : (a) zonally integrated meridional transport cumulated from the bottom upward (Sv) in ERNA (solid line), ORCA_REF (dash-dotted line) and RAPID observa- 
1332 tions (dashed line, http://www.noc.soton.ac.uk/rapidmoc/) and (b) $\sigma_{0}$ zonal $13 з 3$ mean differences $\left(\mathrm{kg} \mathrm{m}^{-3}\right)$ between ERNA and ORCA_REF (calculated over 1334 the full section, dashed line, and in the western part only, solid line).

1335 


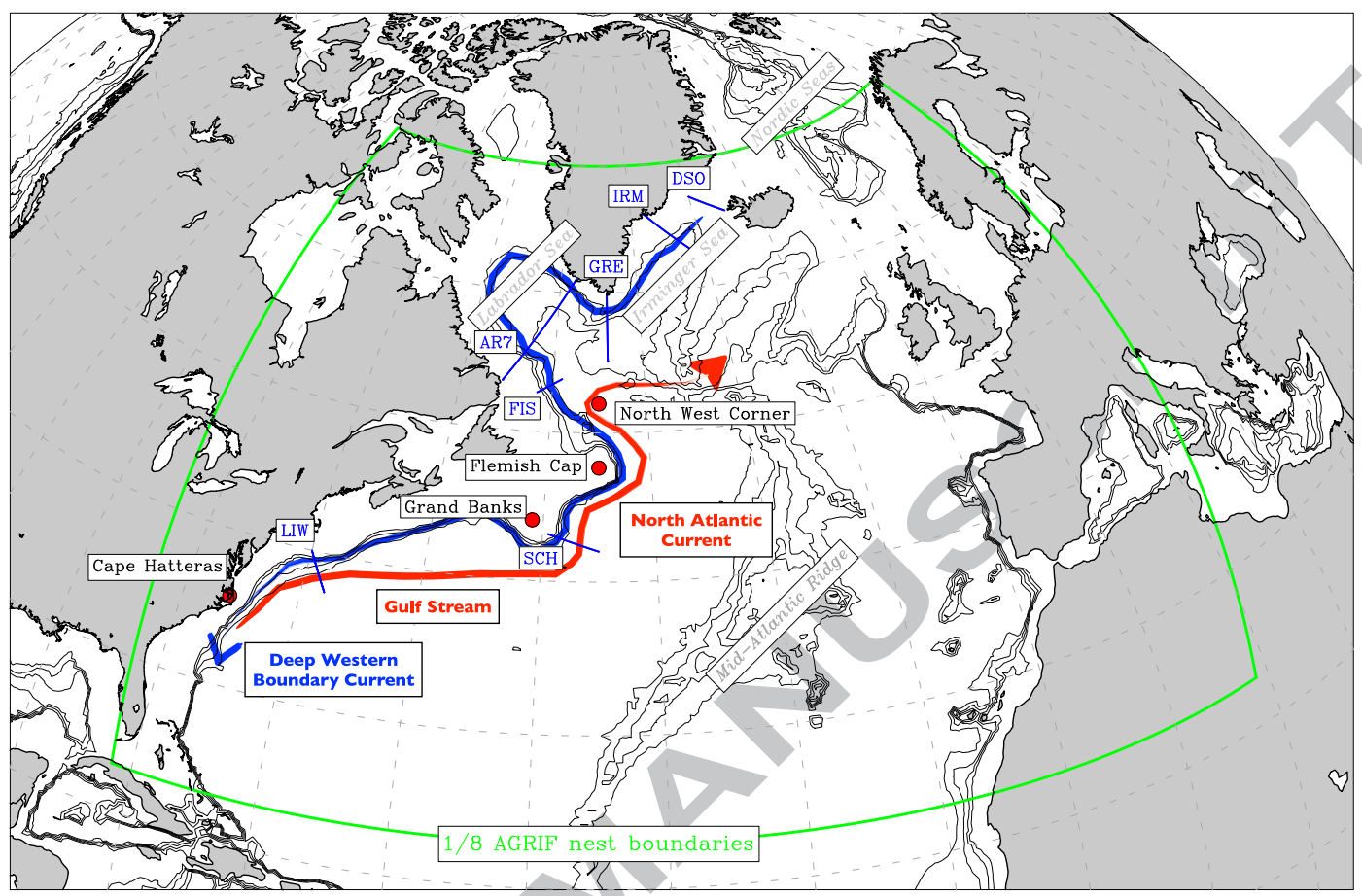

Figure 1: Area covered by the $1 / 8^{\circ}$ nest over the North Atlantic in ERNA configuration, with a schematic location of major western boundary currents at the surface (red thick line) and at depth (blue thick line). Thin blue lines represent vertical sections location; LIW refers to "LineW" (Toole et al., 2011); SCH refers to Schott et al. (2006) section at $43^{\circ} \mathrm{N}$; FIS refers to Fischer et al. (2010) section at $53^{\circ} \mathrm{N}$; AR7 refers to the AR7W section in the Labrador Sea (Hall et al., 2013) and the DSO section through the Denmark Strait overflow (Vage et al., 2011b). 


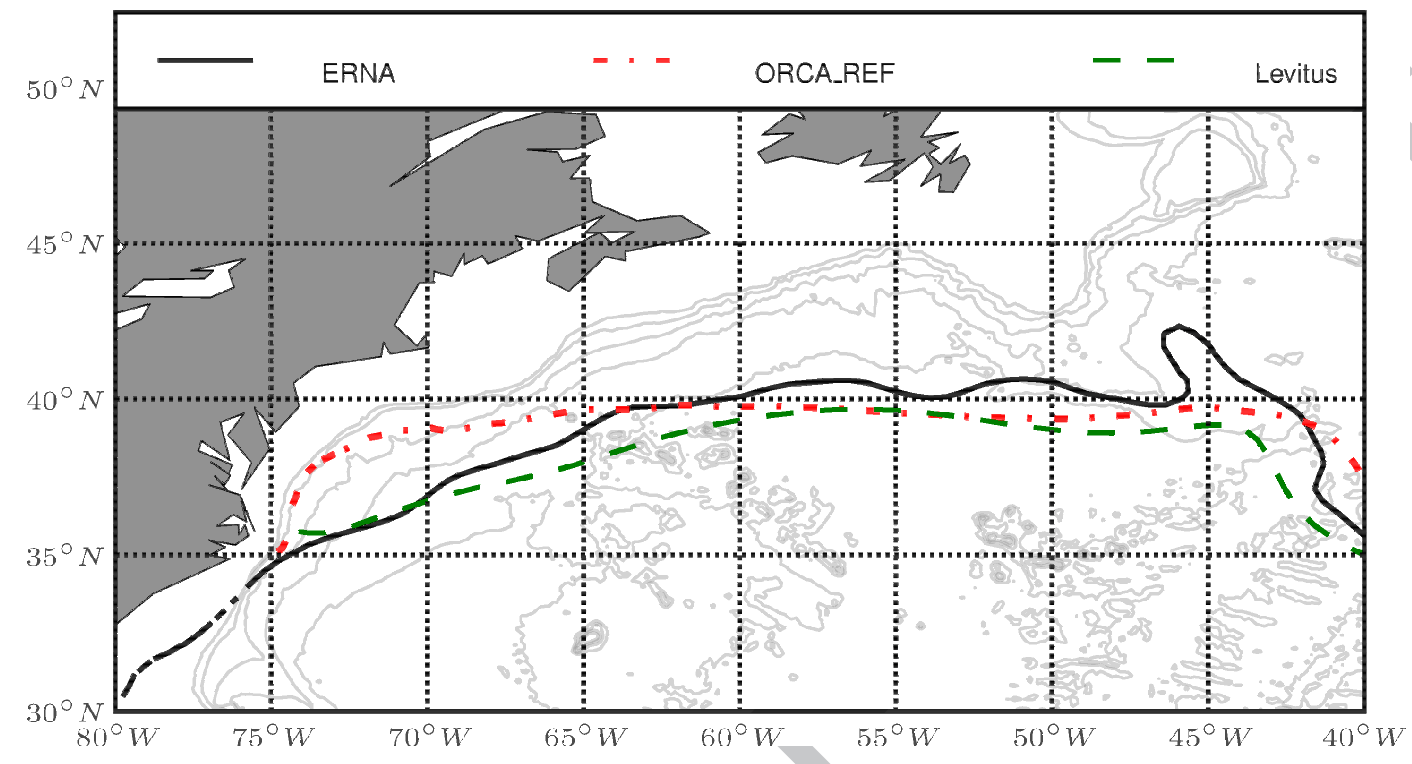

Figure 2: Position of the Gulf Stream as indicated by the $17^{\circ} \mathrm{C}$ isotherm at $177 \mathrm{~m}$ depth, averaged over the period 1990-2009, in simulations and observed climatology. Isobath contours $[1000,2000,3000,4000,5000] \mathrm{m}$ are drawn in thin grey lines. 

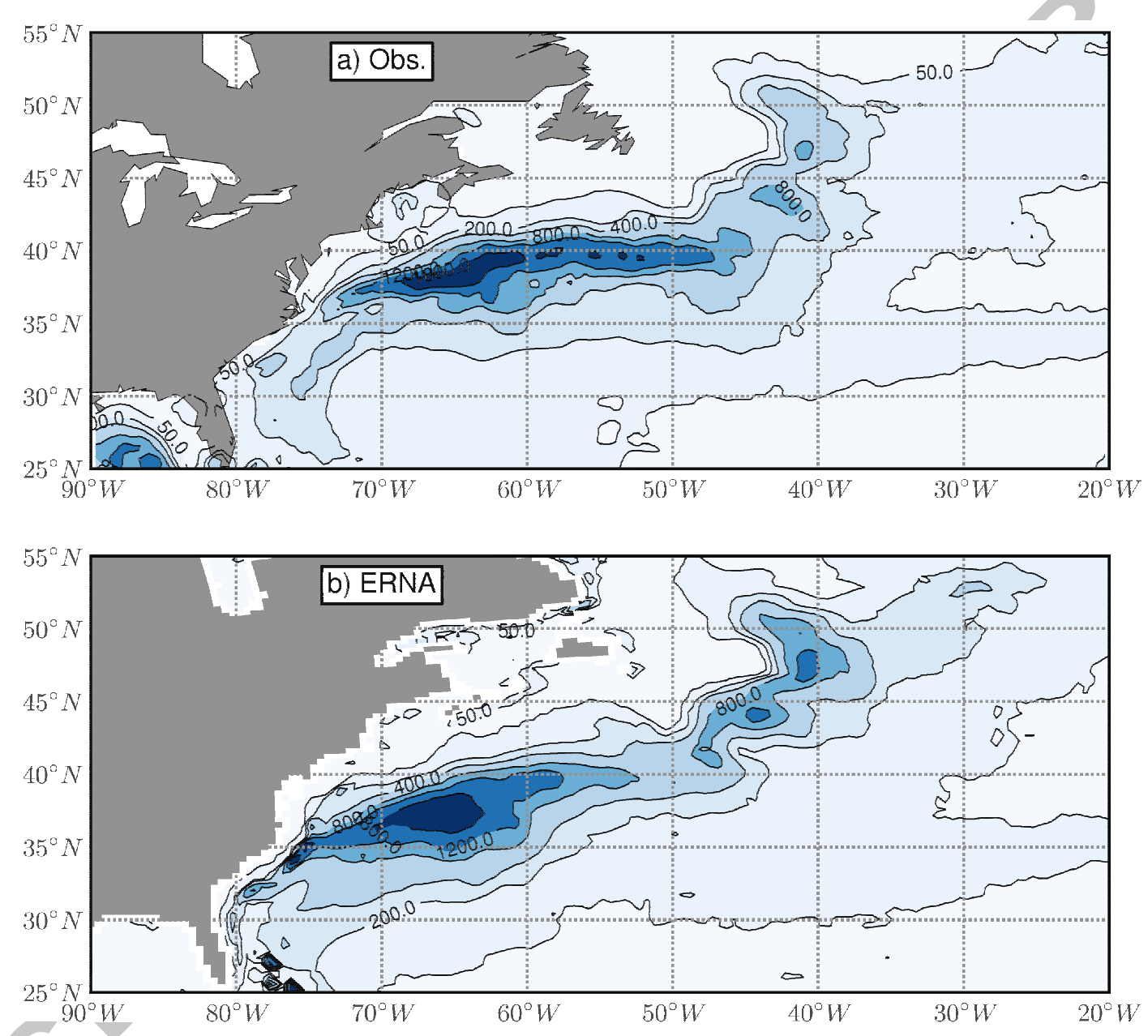

Figure 3: Eddy Kintetic Energy (EKE) averaged over the period 1993-2009 in AVISO observations (a) and ERNA (b) in $\mathrm{cm}^{2} s^{-2}$. 

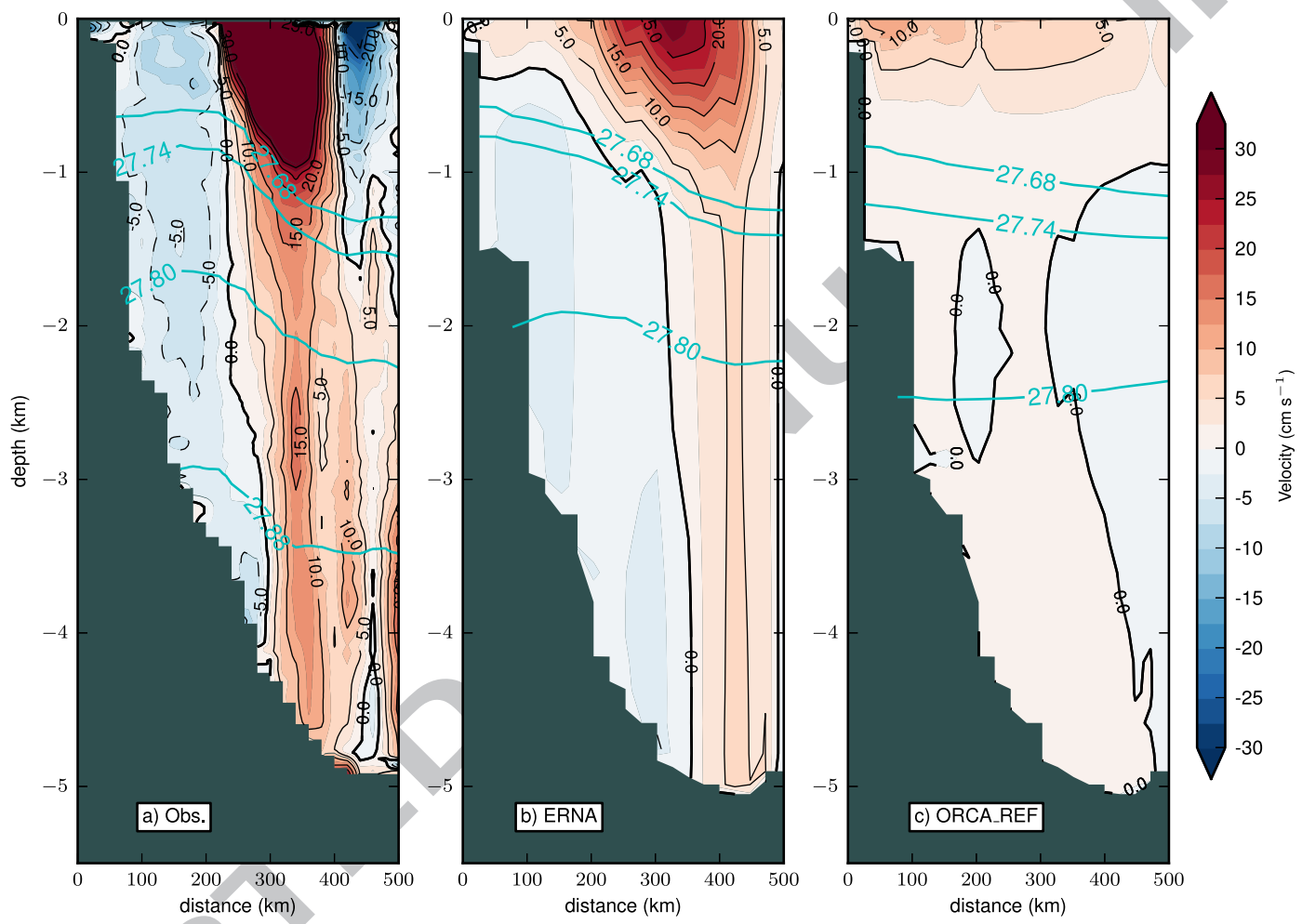

Figure 4: Cross section velocities $\left(\mathrm{cm} \mathrm{s}^{-1}\right.$, C.I $\left.5 \mathrm{~cm} \mathrm{~s}^{-1}\right)$ through Line W (located on Fig. 1), in observations (a), ERNA (b) and ORCA_REF (c) with overlaid $\sigma_{0}$ isopycnals (blue contours density in $\mathrm{kg} \mathrm{m}^{-3}$. Observations are an average from all occupations of LineW, while simulation outputs are averaged over the period 1990-2009. 

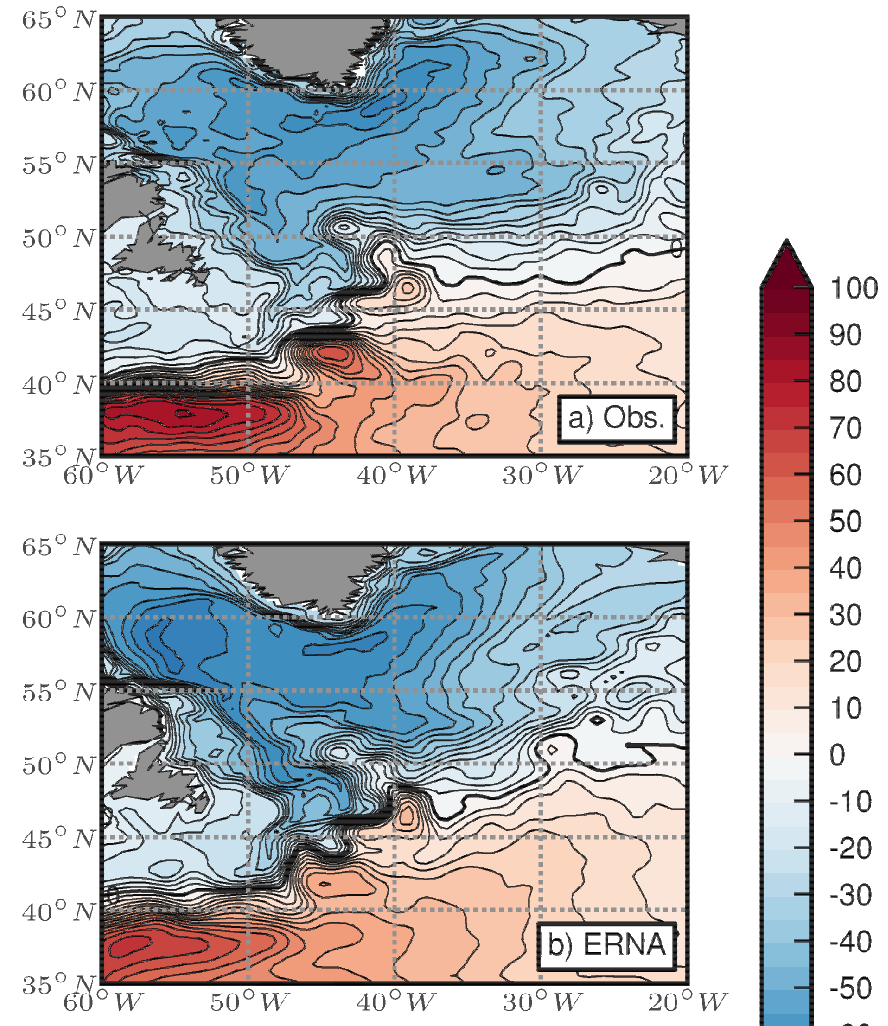

$\begin{array}{rl}-50 & \\ -10 & \\ 30 & \\ 20 & \\ 10 & \widehat{E} \\ 0 & \frac{T}{D} \\ -10 & 0\end{array}$

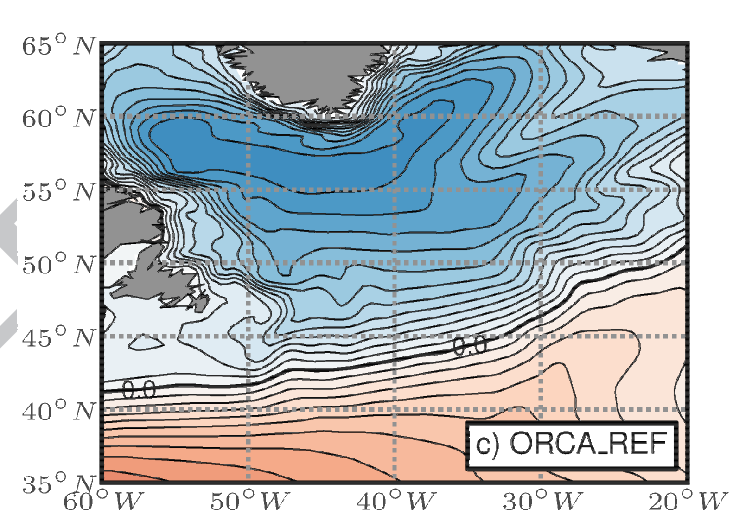

Figure 5: Sea Surface Height (SSH) averaged over the period 1993-2009 in AVISO observations (a), ERNA (b) and ORCA_REF (c). Contour interval is $5 \mathrm{~cm}$. 

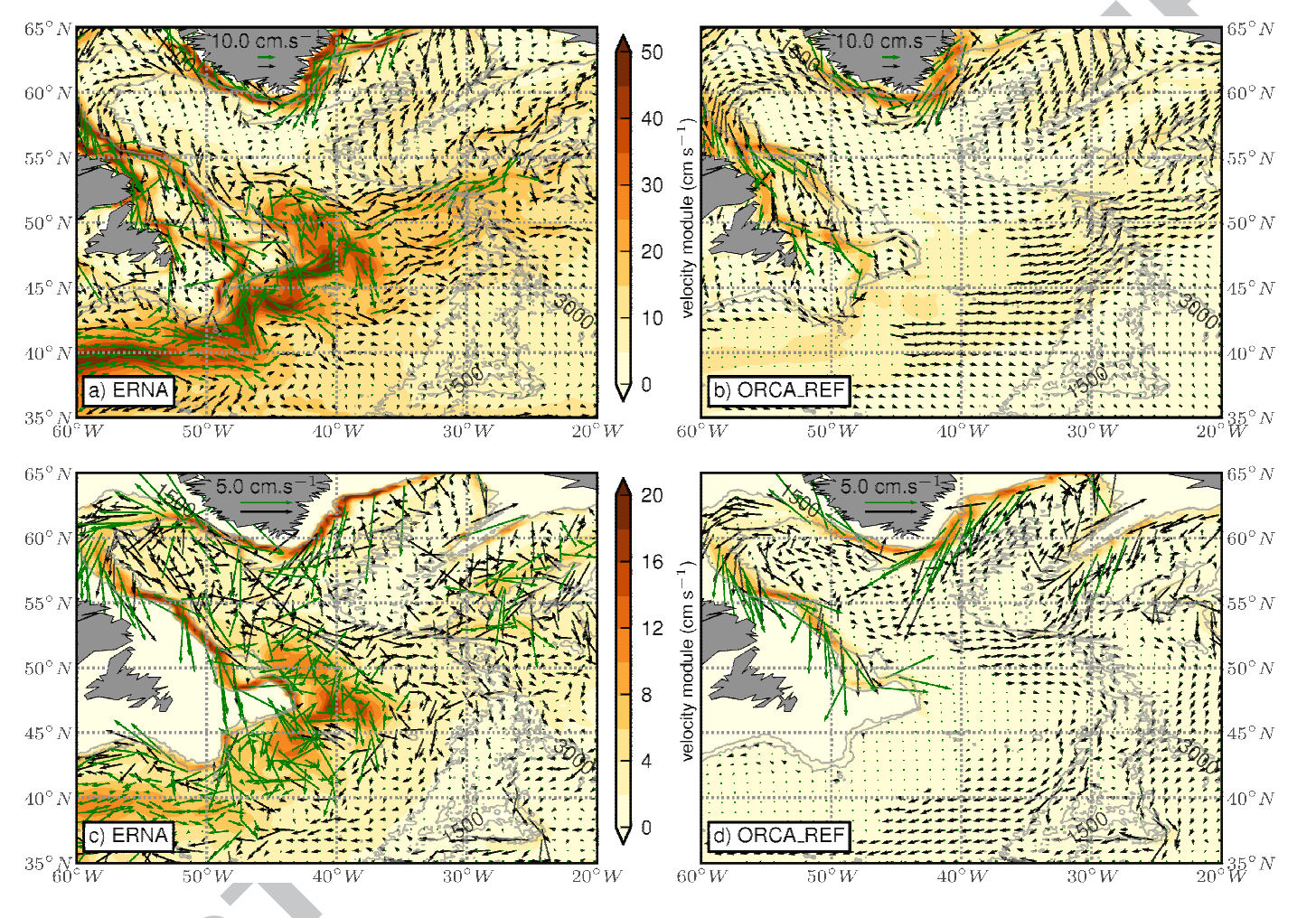

Figure 6: Velocity fields in ERNA (a,c) and ORCA_REF (b,d) at the surface (top panels) and at $1511 \mathrm{~m}$ depth (bottom panels), averaged over the years 1990-2009. The background color corresponds to the modulus of velocity. Currents larger than $10 \mathrm{~cm} \mathrm{~s}^{-1}$ at the surface and $5 \mathrm{~cm} \mathrm{~s}^{-1}$ at depth are rescaled to the respective current speed threshold and shown in green. 

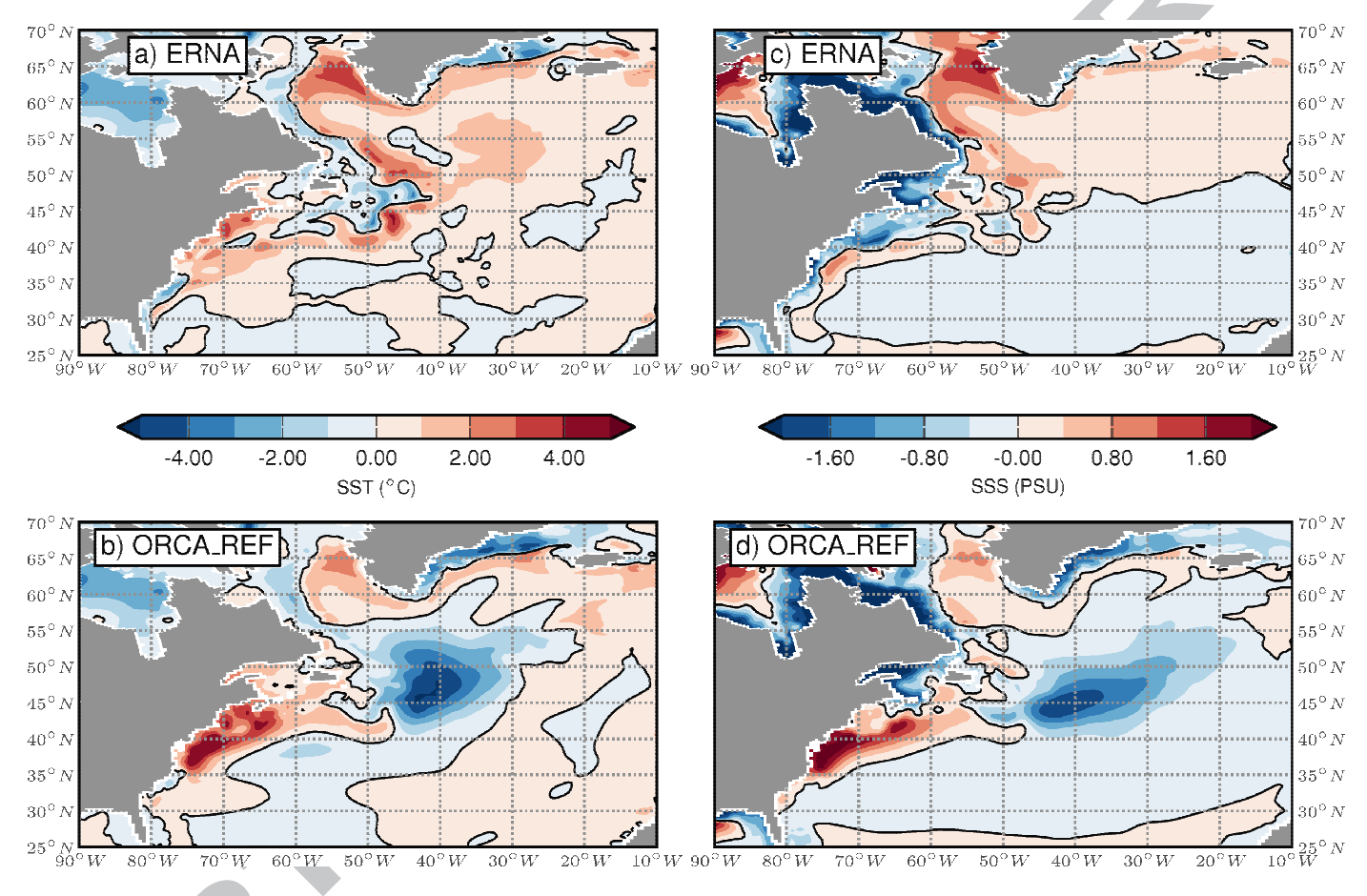

Figure 7: Sea Surface Temperature (SST) (a,b) and Sea Surface Salinity (SSS) (c,d) anomalies to observed Levitus climatology (in ${ }^{\circ} \mathrm{C}$ and PSU) in ERNA (a,c) and ORCA_REF $(b, d)$, averaged over the period 1990-2009. 

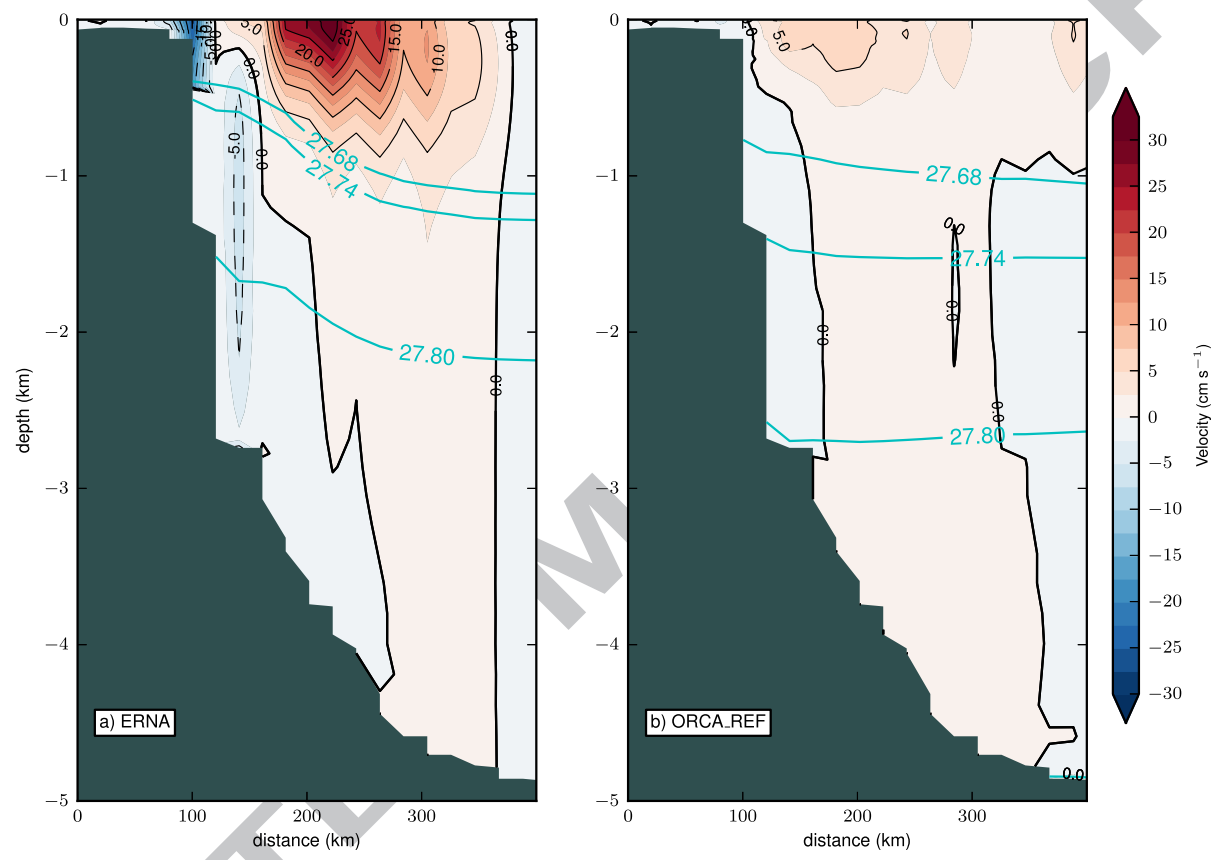

Figure 8: Cross section velocities ( $\mathrm{cm} \mathrm{s}^{-1}$, C.I $5 \mathrm{~cm} \mathrm{~s}^{-1}$ ) through $\mathrm{SCH}$ (located on Fig. 1), in ERNA (a) and ORCA_REF (b) with overlaid $\sigma_{0}$ isopycnals (blue contours density in $\mathrm{kg} \mathrm{m}^{-3}$ ). Simulation outputs are averaged over the period 1990-2009. 


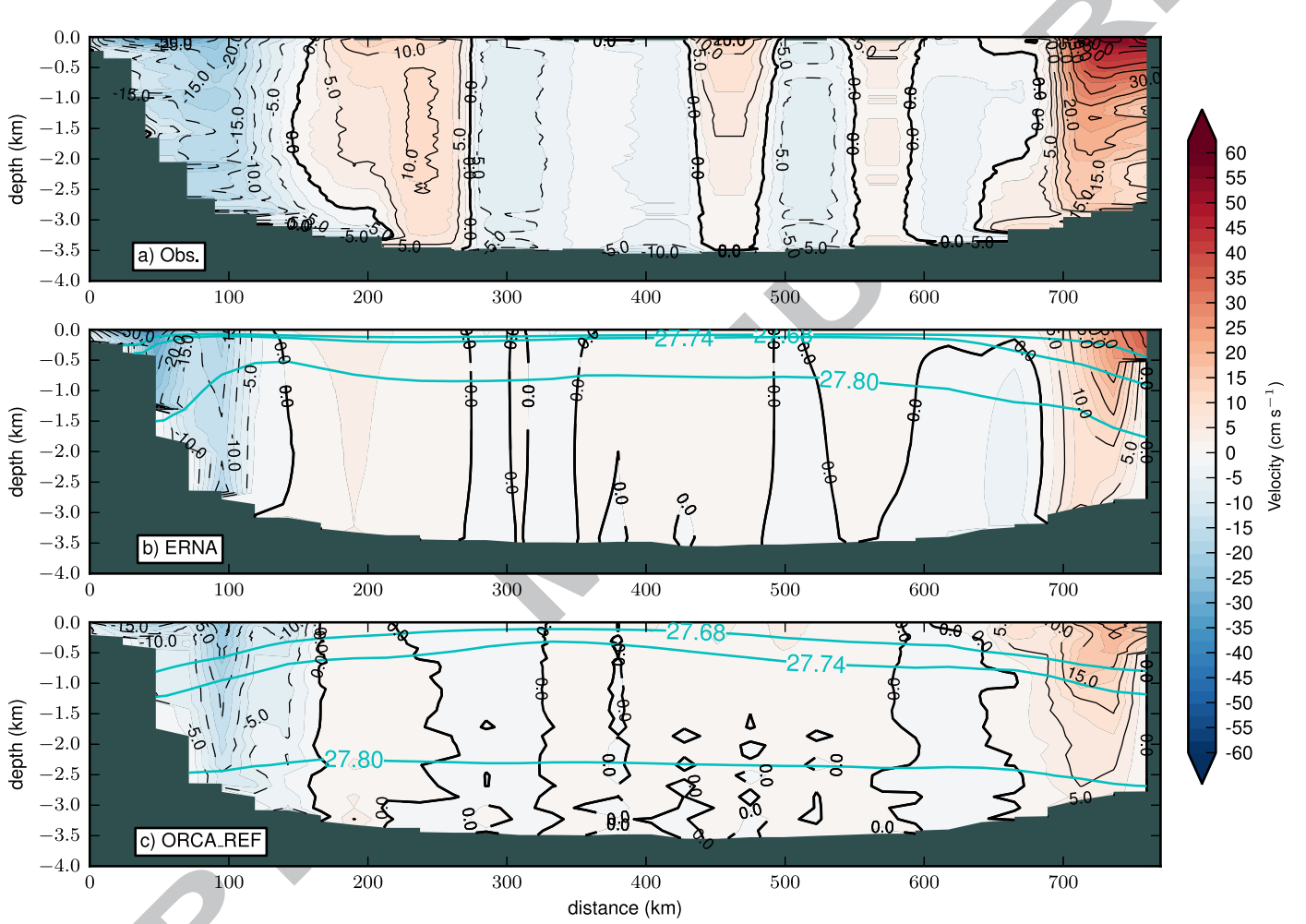

Figure 9: Same as Fig. 4 for section AR7. Observations are composites of repeated measurements [1995-1996-1998-2001-2003-2008] (Hall et al., 2013). 


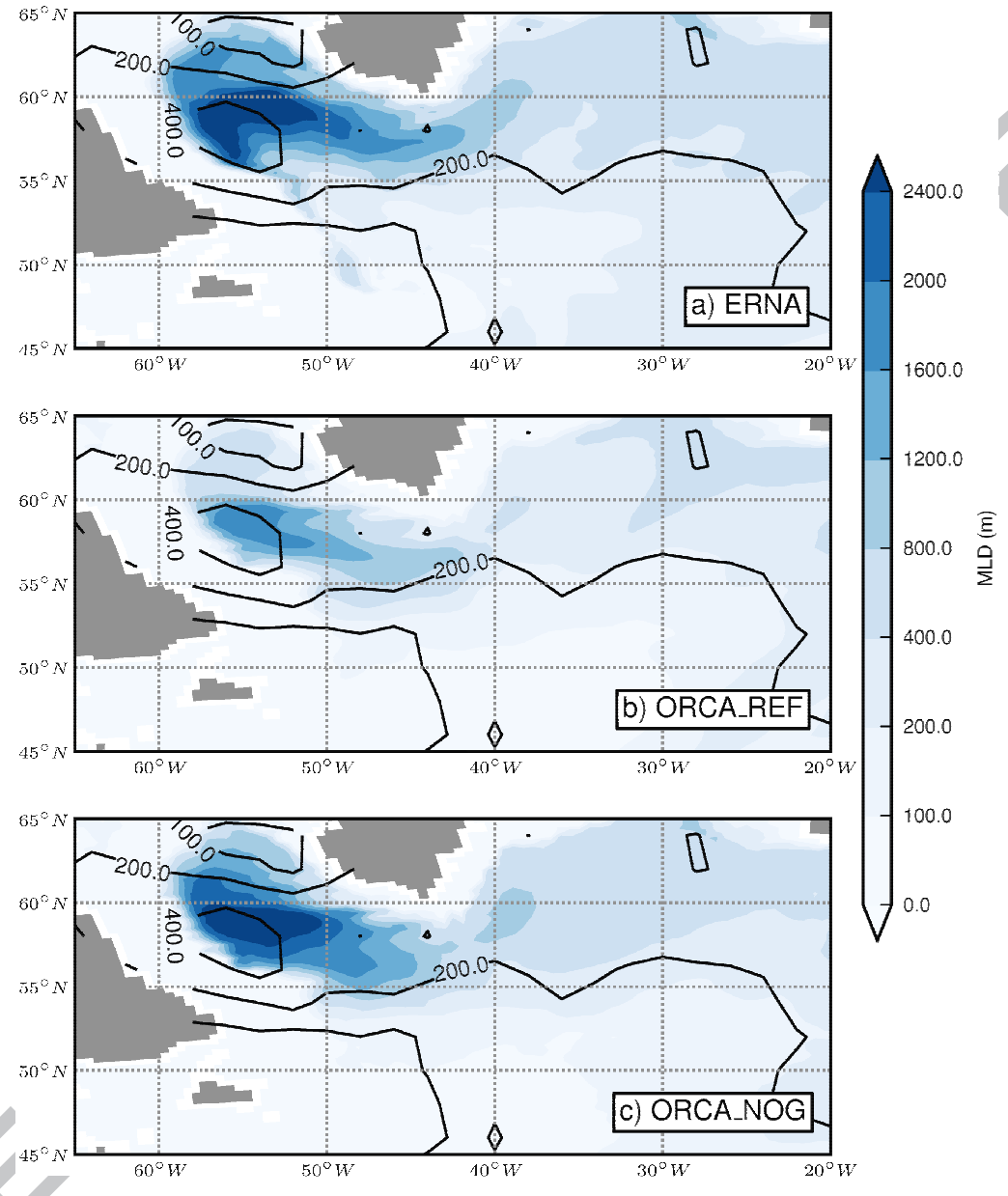

Figure 10: Winter (February-April) Mixed Layer Depth (m) over the period 1990-2009 in the Labrador and Irminger Seas in ERNA (a), ORCA_REF (b) and ORCA_NOG (c). Black contours represent (de Boyer Montégut, 2004) climatology. 

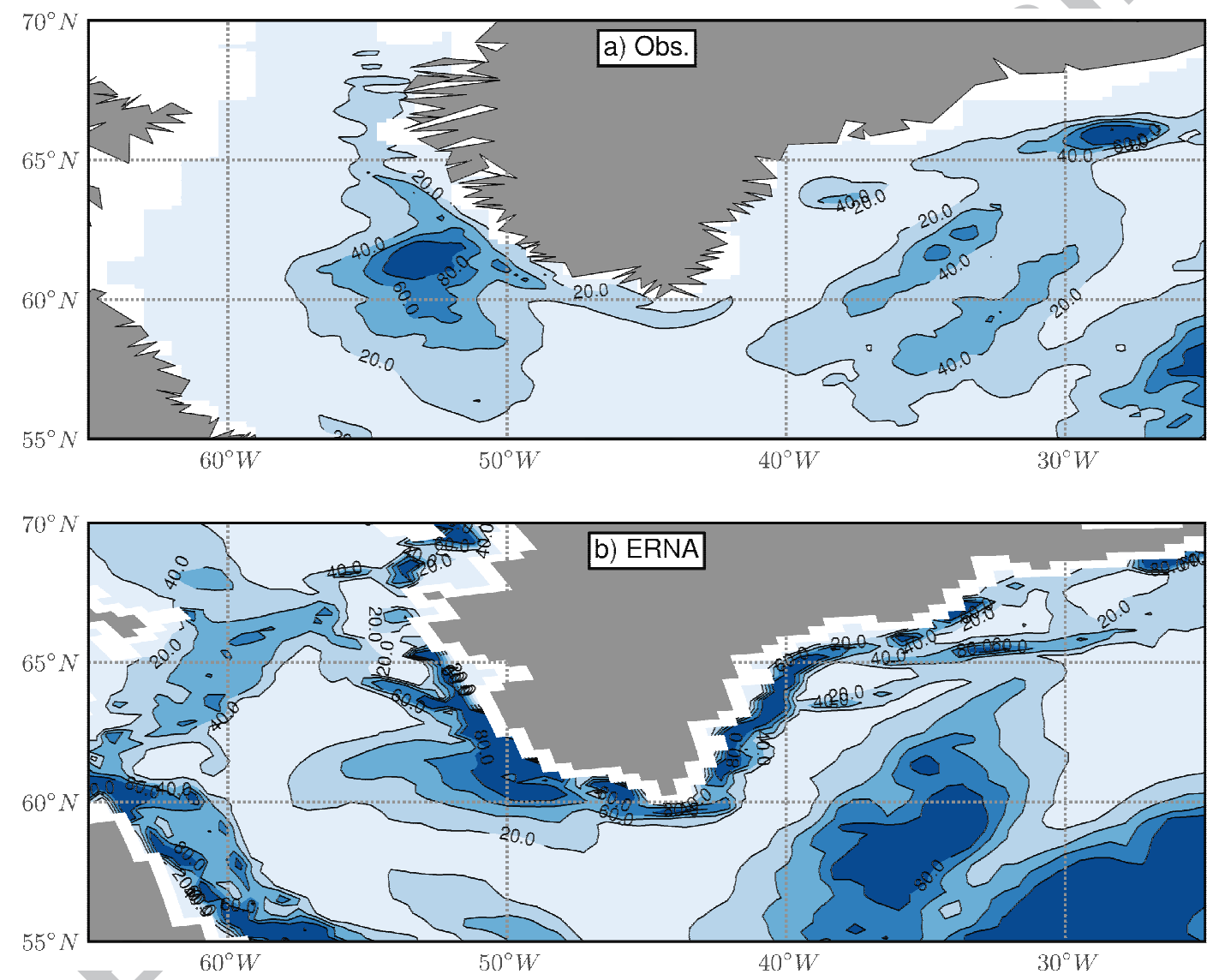

Figure 11: Same as Fig. 3 for the subpolar gyre. 


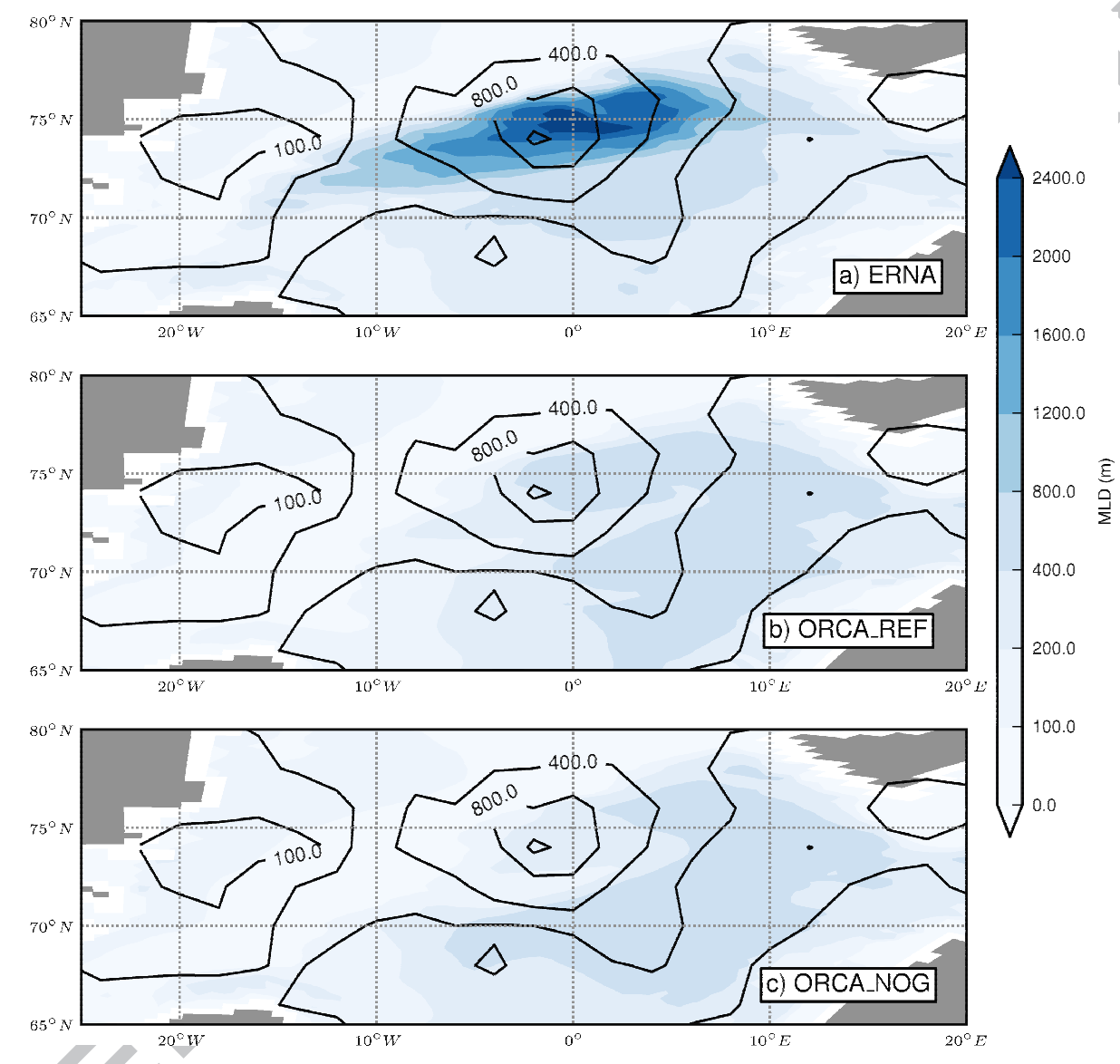

Figure 12: Winter (February-April) Mixed Layer Depth (m) over the period 1990-2009 in Nordic Seas in ERNA (a), ORCA_REF (b) and ORCA_NOG (c). Black contours represent (de Boyer Montégut, 2004) climatology. 

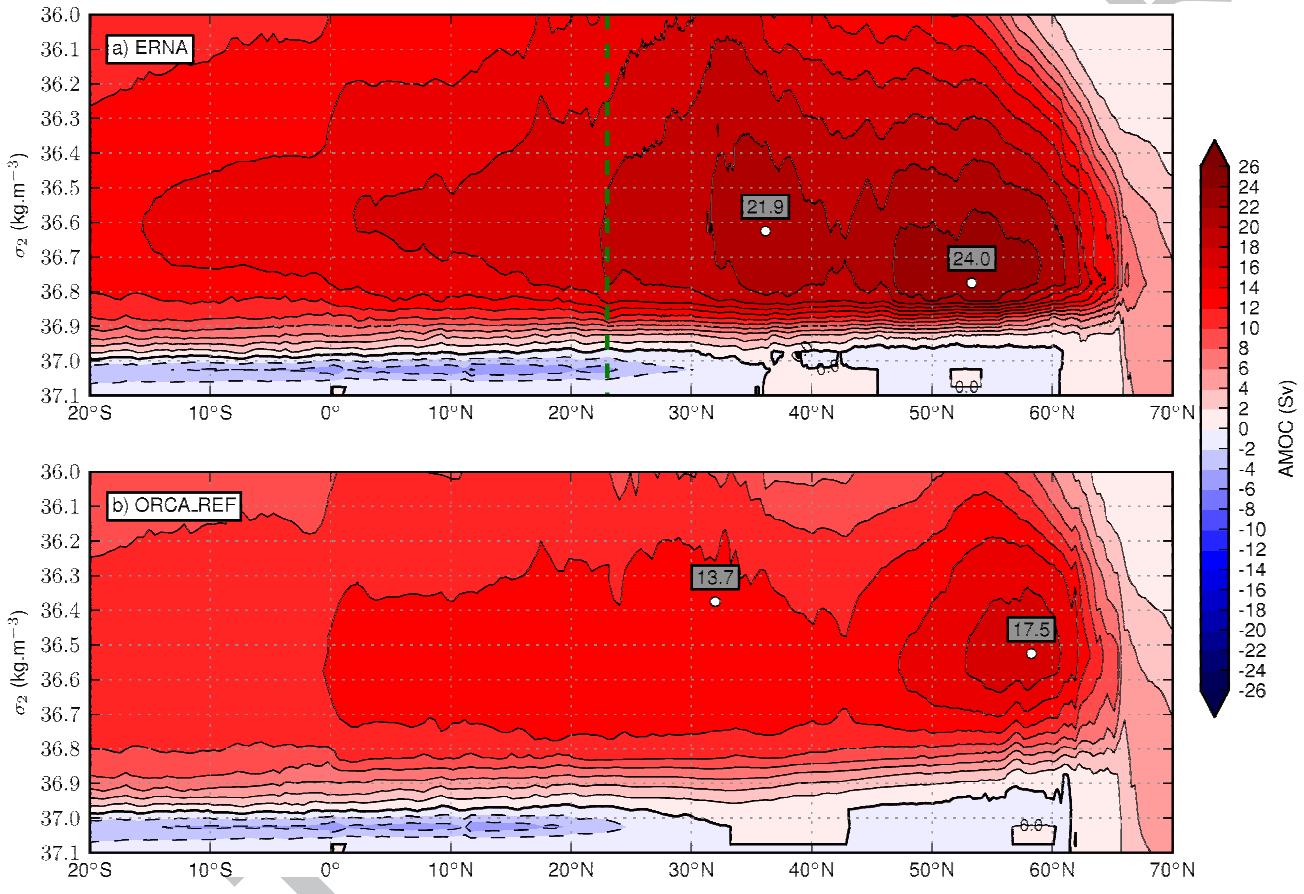

Figure 13: AMOC in $\sigma_{2}$ coordinates averaged over the period 1990-2009 in ERNA (a) and ORCA_REF (b). Contour interval is $2 \mathrm{~Sv}$. Vertical green dashed line locates the south boundary of the nest. 

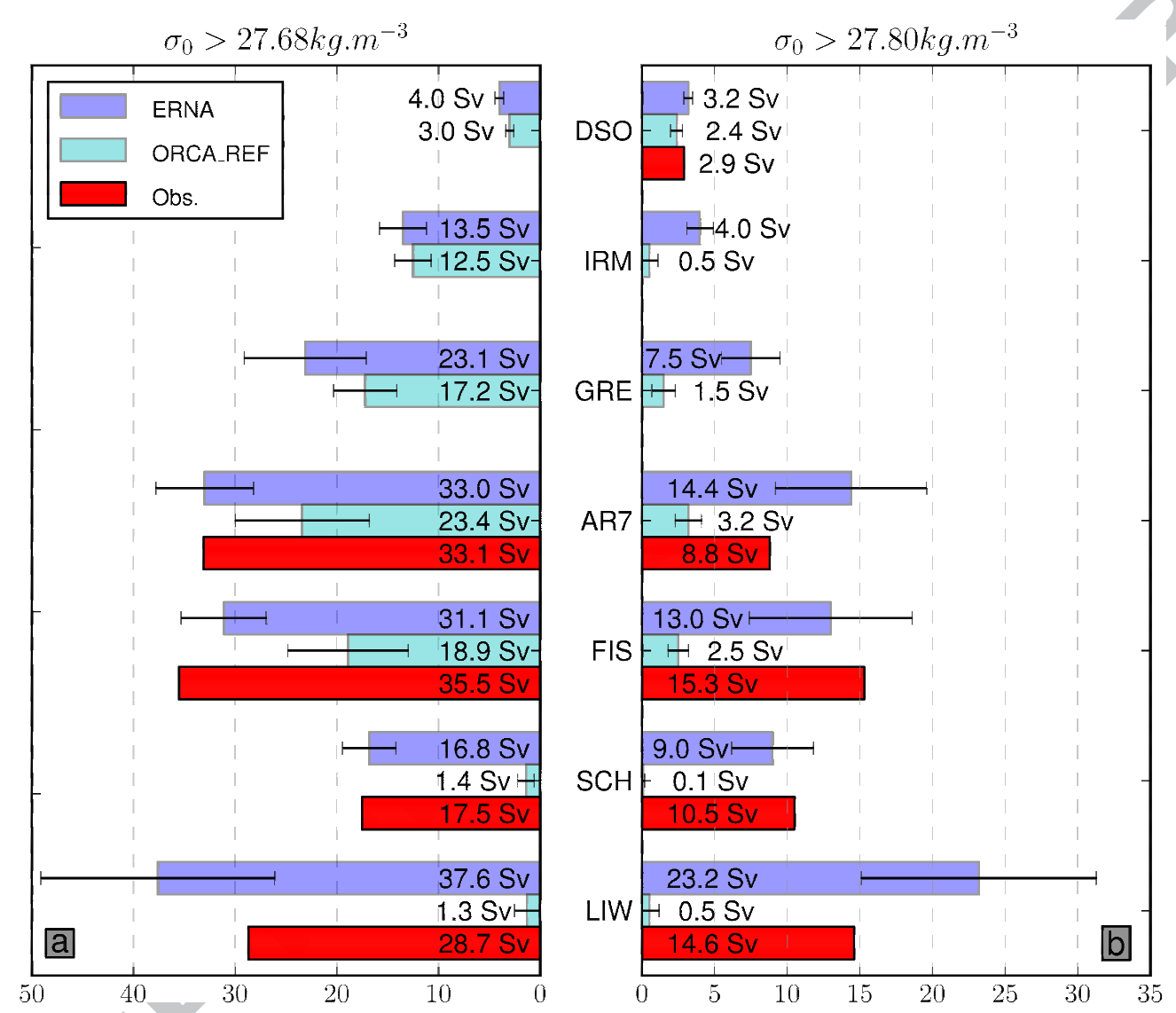

Figure 14: DWBC transport for $\sigma_{0}>27.68 \mathrm{kgm}^{-3}$ (a) and $\sigma_{0}>27.80 \mathrm{kgm}^{-3}$ (b) through sections indicated in Fig.1 (whiskers indicate the standard deviation). Observations are taken from Vage et al. (2011a) for DSO, Hall et al. (2013) for AR7, Fischer et al. (2010) for FIS, Schott et al. (2006) for SCH, Toole et al. (2011) for LIW. 


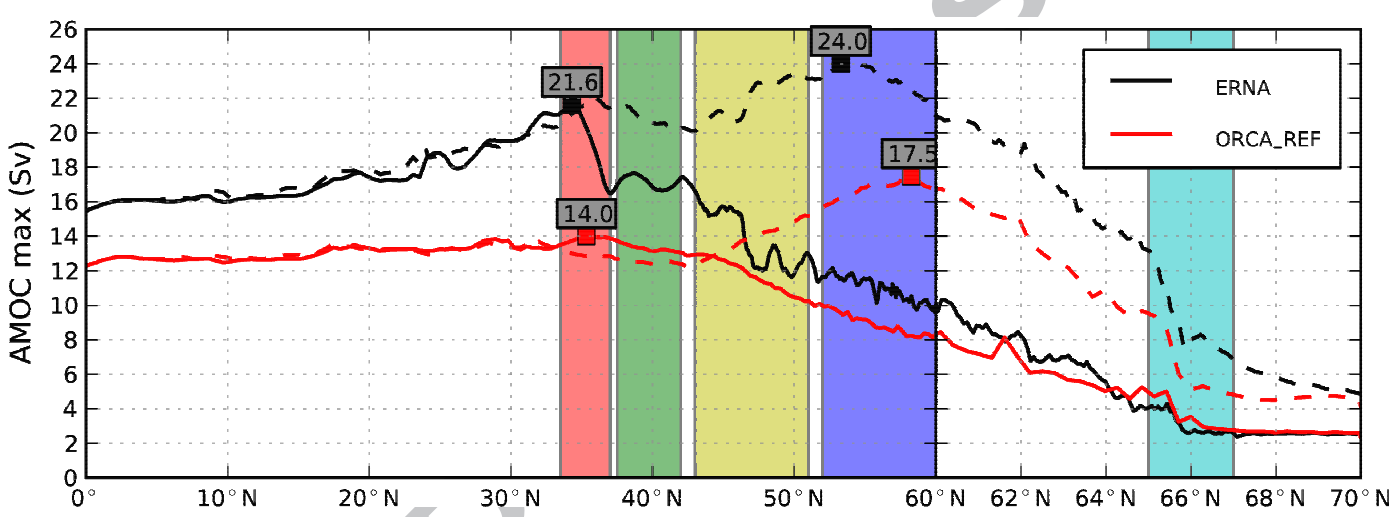

Figure 15: ERNA (black) and ORCA_REF(red) AMOC maximum at each latitude calculated in depth (solid lines) and density $\left(\sigma_{2}\right.$, dash lines) space over the period 1990-2009. Shaded color bands are used in the text for clarity. 

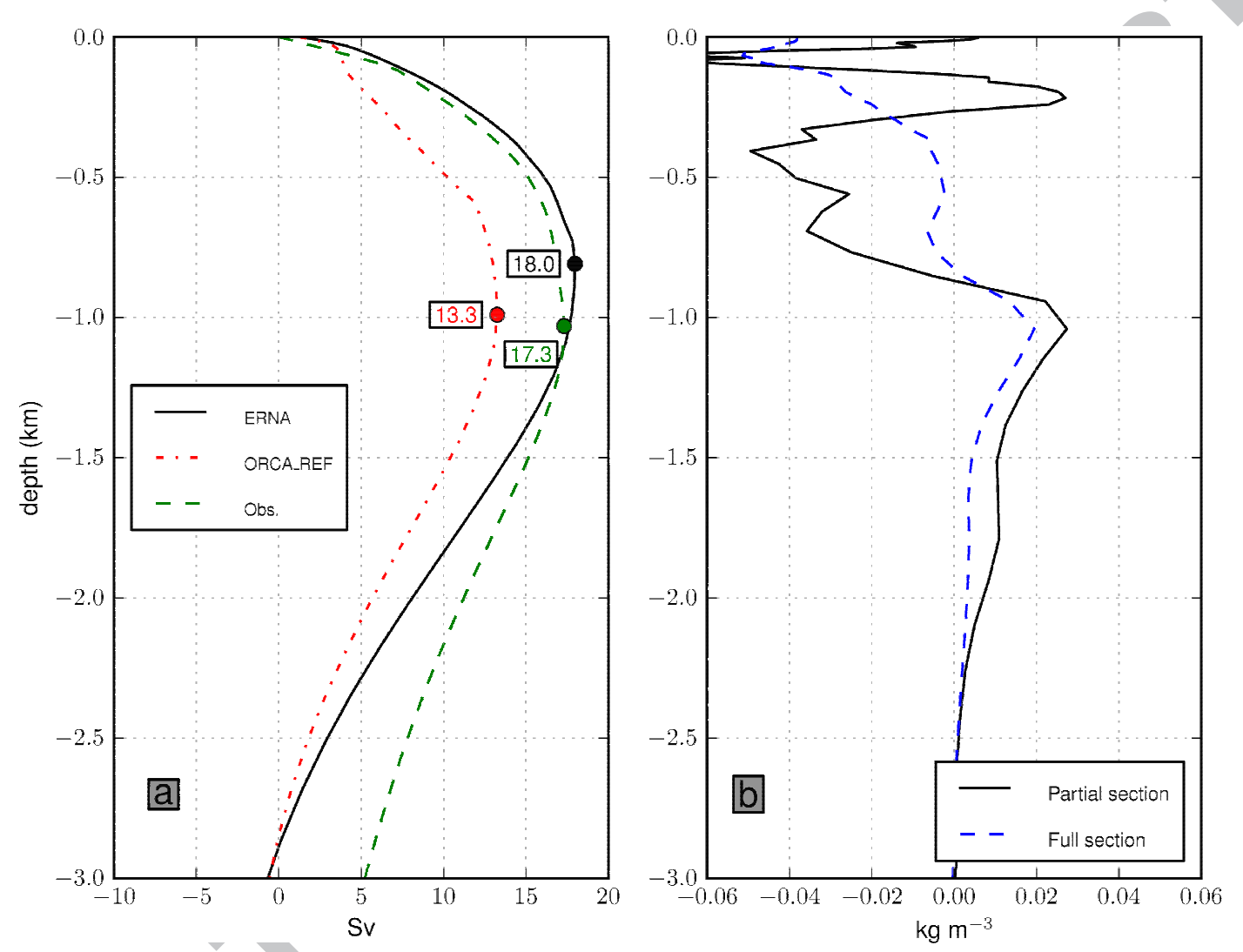

Figure 16: Thermohaline and circulation characteristics at $26.5^{\circ} \mathrm{N}$ : (a) zonally integrated meridional transport cumulated from the surface downward (Sv) in ERNA (solid line), ORCA_REF (dash-dotted line) and RAPID observations (dashed line, http://www.noc.soton.ac.uk/rapidmoc/) and (b) $\sigma_{0}$ zonal mean differences $\left(\mathrm{kg} \mathrm{m}^{-3}\right)$ between ERNA and ORCA_REF (calculated over the full section, dashed line, and in the western part only, solid line). 